\title{
Broadband measurements of aerosol extinction in the ultraviolet spectral region
}

\author{
R. A. Washenfelder ${ }^{1,2}$, J. M. Flores ${ }^{3}$, C. A. Brock ${ }^{2}$, S. S. Brown ${ }^{2}$, and Y. Rudich \\ ${ }^{1}$ Cooperative Institute for Research in Environmental Sciences, University of Colorado, 216 UCB, Boulder, CO 80309, USA \\ ${ }^{2}$ Chemical Sciences Division, Earth System Research Laboratory, National Oceanic and Atmospheric Administration, \\ 325 Broadway, Boulder, CO 80305, USA \\ ${ }^{3}$ Weizmann Institute of Science, Environmental Science Department, Rehovot 76100, Israel
}

Correspondence to: R. A. Washenfelder (rebecca.washenfelder@noaa.gov)

Received: 5 December 2012 - Published in Atmos. Meas. Tech. Discuss.: 3 January 2013

Revised: 6 March 2013 - Accepted: 7 March 2013 - Published: 3 April 2013

\begin{abstract}
Aerosols influence the Earth's radiative budget by scattering and absorbing incoming solar radiation. The optical properties of aerosols vary as a function of wavelength, but few measurements have reported the wavelength dependence of aerosol extinction cross sections and complex refractive indices. We describe a new laboratory instrument to measure aerosol optical extinction as a function of wavelength, using cavity enhanced spectroscopy with a broadband light source. The instrument consists of two broadband channels which span the 360-390 and 385-420 nm spectral regions using two light emitting diodes (LED) and a grating spectrometer with charge-coupled device (CCD) detector. We determined aerosol extinction cross sections and directly observed Mie scattering resonances for aerosols that are purely scattering (polystyrene latex spheres and ammonium sulfate), slightly absorbing (Suwannee River fulvic acid), and strongly absorbing (nigrosin dye). We describe an approach for retrieving refractive indices as a function of wavelength from the measured extinction cross sections over the $360-420 \mathrm{~nm}$ wavelength region. The retrieved refractive indices for PSL and ammonium sulfate agree within uncertainty with the literature values for this spectral region. The refractive index determined for nigrosin is 1.78 $( \pm 0.03)+0.19( \pm 0.08) i$ at $360 \mathrm{~nm}$ and $1.63( \pm 0.03)+0.21$ $( \pm 0.05) i$ at $420 \mathrm{~nm}$. The refractive index determined for Suwannee River fulvic acid is $1.71( \pm 0.02)+0.07( \pm 0.06) i$ at $360 \mathrm{~nm}$ and $1.66( \pm 0.02)+0.06( \pm 0.04) i$ at $420 \mathrm{~nm}$. These laboratory results support the potential for a field instrument capable of determining ambient aerosol optical extinction, average aerosol extinction cross section, and complex refractive index as a function of wavelength.
\end{abstract}

\section{Introduction}

Atmospheric aerosols modify the Earth's energy budget directly by absorbing and scattering solar radiation and indirectly by modifying cloud properties (IPCC, 2007). Aerosol direct forcing remains one of the largest uncertainties in quantifying the role that aerosols play in the Earth's radiative budget (McComiskey et al., 2008). The interaction of light with a particle is determined by the wavelength of the incident radiation, as well as the size, shape, and complex refractive index $(m)$ of the particle. The complex refractive index is the only intrinsic optical property of a particle, while size, shape, and composition are intrinsic physical and chemical properties. Knowing the value of $m$ is critical in correctly modeling the optical properties of aerosols. The complex refractive index of different aerosol types is directly used in regional and global aerosol models to predict aerosol radiative forcing.

Depending on their refractive index, different aerosol types have different influences on the Earth's radiative budget. Most common inorganic aerosols, including sulfate and sea salt, are purely scattering at visible and ultraviolet wavelengths, and thus exert a net cooling effect (Toon et al., 1976; Nilsson, 1979). Alternatively, black carbon aerosols derived from combustion sources strongly absorb light at all visible and ultraviolet wavelengths (Bond and Bergstrom, 2006). Between these two extremes lie brown carbon aerosols, which comprise a potentially large and variable group of organic compounds, including secondary organic and biomass burning aerosols, and which are characterized by a wavelength-dependent absorption that increases toward the 
ultraviolet spectral region (Andreae and Gelencsér, 2006; Sun et al., 2007a; Dinar et al., 2008; Hecobian et al., 2010; Adler et al., 2010; Moosmüller et al., 2011; Zhang et al., 2011). Brown carbon may dominate the aerosol composition in some geographical regions, yet its short-wavelength optical properties are poorly characterized (Chung et al., 2012).

Conventional techniques to measure aerosol scattering and absorption coefficients include integrating nephelometry (Heintzenberg and Charlson, 1996) and filter-based photometry (Bond et al., 1999), respectively. Wavelengthdependent measurements of aerosol optical properties have typically used filter-based collection or extraction methods, rather than direct, in situ methods. For example, commercial aethalometer instruments have provided filter-based measurements over a wide spectral range of discrete wavelengths (e.g., Rizzo et al., 2011), but may be subject to artifacts, for example due to particles on the filter (Weingartner et al., 2003). Recent advances in photo-acoustic spectroscopy (PAS) (Arnott et al., 1999; Lack et al., 2006, 2012) and cavity ring-down spectroscopy (CRDS) (Strawa et al., 2003; Baynard et al., 2007; Abo Riziq et al., 2008; Langridge et al., 2011) allow rapid, accurate, in situ measurements of optical absorption and extinction, but have so far been limited to single, discrete wavelengths. Similarly, cavity attenuated phase shift spectroscopy (CAPS) instruments may employ broadband LED light sources, but do not resolve the extinction as a function of wavelength (Kebabian et al., 2007; Massoli et al., 2010). Due in part to these limitations, there have been few investigations of ambient aerosol optical properties at the blue end of the visible spectrum and into the ultraviolet, where some aerosol types both scatter and absorb light (Bond, 2001; Sun et al., 2007b). One existing instrument combines a White-type multipass gas cell with a grating and a linear diode array detector to measure aerosol extinction as a function of wavelength from the mid-infrared to nearultraviolet spectral region (Chartier and Greenslade, 2012). Further development of sensitive and accurate instruments able to measure extinction continuously across a broad wavelength region, particularly in the near ultraviolet and blue end of the visible spectrum, provides a useful complement to existing PAS, CRDS, and CAPS instruments.

Recent advances in cavity enhanced spectroscopy have combined high-intensity, broadband light sources with optical cavities. The optical output from the cavity is resolved with a spectrometer and recorded using a multichannel detector. This approach allows sensitive measurements of optical extinction as a function of wavelength (Fiedler et al., 2003). For gas-phase absorption measurements, the technique is referred to as incoherent broadband cavity enhanced absorption spectroscopy (IBBCEAS or BBCEAS), or alternatively as cavity enhanced differential optical absorption spectroscopy (CE-DOAS) (Platt et al., 2009). IBBCEAS is a sensitive and selective detection method for atmospheric trace gases with broad, structured absorptions in the visible and ultraviolet spectral region. When the optical cross section of the analyte species is known, the gas-phase concentration of the species may be calculated directly from the optical extinction. IBBCEAS has been used successfully to measure gas phase concentrations of $\mathrm{NO}_{2}, \mathrm{NO}_{3}, \mathrm{CHOCHO}$, $\mathrm{CH}_{3} \mathrm{COCHO}, \mathrm{HONO}, \mathrm{O}_{3}, \mathrm{I}_{2}$, IO, and OIO (Ball et al., 2004; Venables et al., 2006; Washenfelder et al., 2008; Gherman et al., 2008; Vaughan et al., 2008; Thalman and Volkamer, 2010). Initial cavity measurements have reported aerosol extinction for ambient aerosol (Washenfelder et al., 2008; Varma et al., 2009; Thalman and Volkamer, 2010).

In this study, we further extend the use of broadband cavity enhanced spectroscopy to measure aerosol extinction as a function of wavelength in a high-finesse cavity. By sizeselecting different aerosol types, it is possible to measure their extinction cross section as a function of wavelength, and directly observe the Mie scattering resonances. For aerosols whose extinction cross section has minimal spectral dependence, the selection and measurement of a single particle diameter allows the retrieval of the complex refractive index (RI). Alternatively, for aerosols whose extinction cross section varies with wavelength, the measurement of several particle sizes allows the retrieval of the complex RI as a function of wavelength. This paper demonstrates this technique for aerosols that are purely scattering (polystyrene latex spheres and ammonium sulfate), slightly absorbing (Suwannee River fulvic acid), and highly absorbing (nigrosin dye). Instead of using the existing acronym of IBBCEAS/BBCEAS, we refer to this method by the more general name of Broadband Cavity Enhanced Spectroscopy (BBCES), because it is a measurement of total optical extinction.

\section{Experimental}

The laboratory instrument consists of two BBCES channels and one CRDS channel, which measure aerosol extinction at 360-390, 385-425, and $407 \mathrm{~nm}$, respectively. The optics, aerosol generation, and flow system are described in detail below and presented schematically in Fig. 1. All of the instrumental components are mounted on a standard laboratory optical bench.

\subsection{Description of the broadband cavity enhanced spectrometer (BBCES) channels}

Each of the two BBCES channels consist of an LED, collimating lens, optical cavity, bandpass filter, and shared grating spectrometer with CCD array detector as shown in Fig. 1a. The laboratory instrument is similar to an instrument for gas phase measurements of glyoxal and nitrogen dioxide described previously in Washenfelder et al. (2008). Notable changes include the addition of a second channel, replacement of the Xenon arc lamp with LEDs, and changes to the collimating and filtering optics (Axson et al., 2011). 


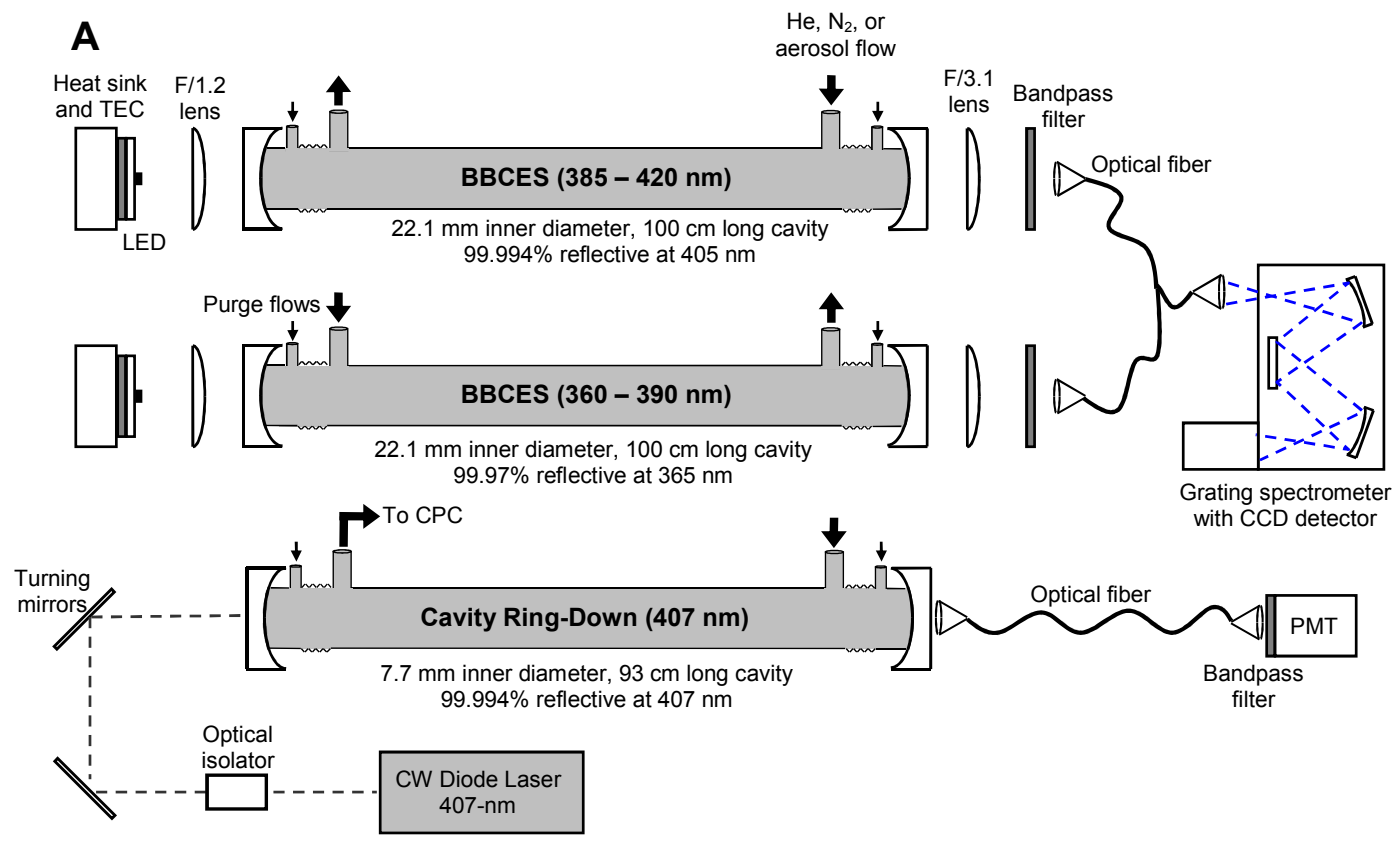

B

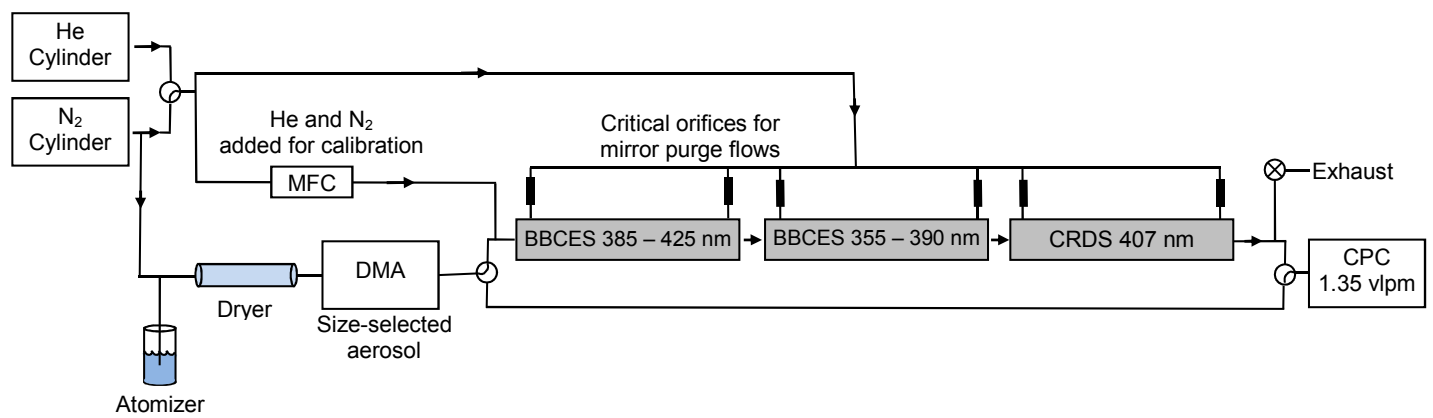

Fig. 1. (a) Schematic of the broadband cavity enhanced spectrometer, with channels for 360-390 and 385-420 nm. Each BBCES channel consists of a temperature-controlled LED and optical cavity, with a shared grating spectrometer. Details of the $407 \mathrm{~nm}$ CRDS are given in Fuchs et al. (2009). (b) Block diagram showing aerosol generation and gas delivery. Aerosols are generated with an atomizer, and subsequently dried and size-selected using a differential mobility analyzer (DMA). The aerosol concentration is measured using a condensation particle counter (CPC).

The first BBCES channel covers the spectral region from 360-390 nm, using an LED with manufacturer-specified center wavelength between 360-370 nm (NCSU033A, Nichia Corp., Tokyo, Japan). The experimentally measured center wavelength and optical power output at $0.5 \mathrm{~A}$ and $20.0^{\circ} \mathrm{C}$ are $370.2 \mathrm{~nm}$ and $0.210 \mathrm{~W}$, respectively. The second BBCES channel covers the spectral region from $385-425 \mathrm{~nm}$, using an LED with manufacturer-specified center wavelength between 390-410 nm (LZ1-00UA05, LEDEngin Inc., San Jose, CA, USA). The experimentally measured center wavelength and optical power output at $0.7 \mathrm{~A}$ and $20.0^{\circ} \mathrm{C}$ are $407.1 \mathrm{~nm}$ and $0.450 \mathrm{~W}$, respectively. To maintain a constant optical power output, the temperature of each LED is controlled at $20.0( \pm 0.3)^{\circ} \mathrm{C}$ and powered by a constant-current power supply.
Each LED is mounted in a fixed position, and collimated with a single F/1.2 fused silica lens mounted on a three-axis translation stage. The collimated light is passively coupled into a cavity consisting of two $2.5 \mathrm{~cm}, 1 \mathrm{~m}$ radius of curvature mirrors (Advanced Thin Films, Boulder, CO, USA). The manufacturer's reported transmission for the two sets of mirrors is $82 \mathrm{ppm}$ at the nominal center wavelength of $362 \mathrm{~nm}$ and $35 \mathrm{ppm}$ at the nominal center wavelength of $405 \mathrm{~nm}$. After exiting the cavity, the light is optically filtered (XB05, Omega Optical Inc, Brattleboro, VT, USA; FB400-40, Thorlabs, Newton, NJ, USA) to block stray light and out-of-band light from the LEDs. The filtered light is imaged by a $2.5 \mathrm{~cm}$ $\mathrm{F} / 3.1$ lens onto a $0.5 \mathrm{~cm} \mathrm{~F} / 2$ lens that couples the light into a fiber bundle (BFB-455-7, Princeton Instruments, Trenton, NJ, USA) containing seven $200 \mu \mathrm{m}$ diameter UV-VIS fibers 
which are then oriented linearly along the $100 \mu \mathrm{m}$ input slit for the grating spectrometer.

Spectra are acquired using a $150 \mathrm{~mm}$ focal length CzernyTurner spectrometer (InSpectrum 150, Princeton Instruments) with a 16-bit back-illuminated $250 \times 1024$ pixel charge coupled device (CCD) array detector cooled to $-20^{\circ} \mathrm{C}$ (Langford et al., 2007). The spectrometer contains a 1200 groove $\mathrm{mm}^{-1}(500 \mathrm{~nm}$ blaze) grating rotated to allow spectral measurements between $333-451 \mathrm{~nm}$. The grating spectrometer is temperature controlled at $33.0( \pm 0.2)^{\circ} \mathrm{C}$. Dark spectra are acquired with the InSpectrum input shutter closed. The wavelength calibration was determined using narrow $\mathrm{Hg}$ emission lines from a $\mathrm{Hg} / \mathrm{Ar}$ lamp, and was consistent within $0.03 \mathrm{~nm}$ over the course of the experiments.

The spectra from the InSpectrum 150 are measured as two vertical regions on the CCD, and digitized to produce two spectra. Custom data acquisition software (Labview, National Instruments Corp., Austin, TX, USA) is used to control the spectrometer and acquire data.

\subsection{Description of the cavity ring-down spectroscopy (CRDS) channel}

The CRDS channel consists of a diode laser, optical cavity, bandpass filter, and photomultiplier tube, following the design in Fuchs et al. (2009). Light from a continuous wave diode laser with temperature-controlled diode (Fabry-Perot diode model IQ $\mu$ series, optical power output $80 \mathrm{~mW}$, Power Technology Inc., Little Rock, AR, USA) is amplitude modulated with a square-wave signal at a repetition of $2 \mathrm{kHz}$ and a duty cycle of $50 \%$. The laser is optically isolated and aligned on-axis to the cavity with no active mode matching. The cavity is formed by a pair of $2.54 \mathrm{~cm}$ diameter, $1 \mathrm{~m}$ radius of curvature mirrors (Advanced Thin Films, Boulder, CO, USA). The center wavelength and full-width at half-maximum of the diode laser were measured with a grating spectrometer to be $407.0( \pm 0.1) \mathrm{nm}$ and $0.6( \pm 0.15) \mathrm{nm}$, respectively. The observed ring-down time constant at $407 \mathrm{~nm}$ was approximately $33 \mu$ s at ambient pressure $(840 \mathrm{hPa}$ in Boulder, CO; $1600 \mathrm{~m}$ above mean sea level). The light transmitted through the end mirror of the cavity is collected with a $200 \mu \mathrm{m}$ diameter fiber optic, optically filtered with a bandpass filter (FB405-10, Thorlabs), and then measured by a photomultiplier tube module (HC120, Hamamatsu Photonics, Hamamatsu, Japan). Ring-down transients are recorded at a repetition rate of $1 \mathrm{kHz}$, coadded, and fitted with a single exponential following the method in Fuchs et al. (2009).

\subsection{Aerosol generation and measurement}

Four different aerosol types were generated: polystyrene latex spheres (PSL; Nanosphere size standards, Thermo Fisher Scientific Inc., Waltham, MA, USA), ammonium sulfate (AS; a component of anthropogenic aerosol; Sigma Aldrich, St. Louis, MO, USA), Suwannee River fulvic acid (SRFA; a model compound for humic-like substances; 1S101F, International Humic Substances Society, Saint Paul, MN, USA), and water-soluble nigrosin (an organic black dye used as a model for highly absorbing substances; CAS 8005-03-6, part number 198285, Sigma Aldrich). As shown in Fig. 1b, an aerosol was atomized from the aqueous solutions of pure compounds in distilled water $\left(2-6 \mathrm{~g} \mathrm{~L}^{-1}\right)$ using a custombuilt Collison-type atomizer (Liu and Lee, 1975) with dry nitrogen flow. The atomizer output was diluted with dry, particle-free nitrogen, and dried with a silica gel diffusion dryer, which reduced the relative humidity to less than $10 \%$. Subsequently, particles were size-selected using a custombuilt differential mobility analyzer (DMA; now available from Brechtel Manufacturing Inc., Hayward, CA, USA) (Knutson and Whitby, 1975). Prior to entering the DMA column, a steady-state charge distribution was achieved using a $20 \mathrm{mCi}$ Po 210 source. The DMA was operated with a fixed applied voltage, a sample flow of $0.3-0.5$ volumetric liters per minute (vlpm), and a ratio of $10: 1$ between the sheath flow and sample flow. The particle concentration after the three optical channels was measured continuously using a condensation particle counter (CPC; 3022A, TSI Inc., Shoreview, MN, USA).

Measurements were performed for particle diameters from 200 to $800 \mathrm{~nm}$ in $100 \mathrm{~nm}$ steps (excluding $700 \mathrm{~nm}$ ) for PSL and in $50 \mathrm{~nm}$ steps for AS, SRFA, and nigrosin. For each measured PSL diameter, the particle loss through the system was both measured and modeled (von der Weiden et al., 2009), with agreement of $1 \%$ between the two methods. The particle loss was included in calculations of the extinction cross section for each cavity, with the assumption that particle loss was evenly divided among the three cavities, which were connected in series.

The uncertainty in the diameter of spherical particles selected by the DMA is $\leq 1 \%$, as determined by measuring the DMA transfer function for five sizes of NIST-traceable PSL standards. Treatment of multiple-charged particles in the size distribution produced by the DMA selection of aerosols generated from solution is described in Sect. 3.3.2.

\subsection{Flow system}

The size-selected aerosol from the DMA was sampled by the three cavities in series, as shown in Fig. 1b. The flow system consisted entirely of aluminum, stainless steel, and conductive silicone tubing to minimize electrostatic particle losses. A constant flow of $1.35( \pm 0.01)$ vlpm through the three cavities was provided by the condensation particle counter. The measured pressure drop through the three cells was less than $0.5 \mathrm{hPa}$. Small $\mathrm{N}_{2}$ purge flows of $35-50$ volumetric $\mathrm{cm}^{3} \mathrm{~min}^{-1}(\mathrm{vccm})$ were added at the mirrors to maintain their cleanliness. These flows were produced using six critical orifices supplied by a regulated $70 \mathrm{kPa}$ of $\mathrm{N}_{2}$. The dilution of the ambient sample by the mirror purge flows was accounted for in the data analysis. Temperature (K-type 
thermocouple) and pressure (PPT, Honeywell, International Inc., Plymouth, MN, USA) were measured at the CRDS cell.

Calibration gases were added by pushing through the system. This method was used to fill the cells with $\mathrm{He}$ and $\mathrm{N}_{2}$, which were used to calculate the mirror reflectivity.

\subsection{Operation}

During normal laboratory operation, the BBCES, CRDS, and aerosol generation and counting instruments were turned on at least $1 \mathrm{~h}$ prior to beginning measurements to allow the temperatures and flows to stabilize. The first step in the measurement sequence was to determine the dark noise of the CCD detector by acquiring spectra under dark conditions, which were then scaled to the integration time and subtracted from subsequent spectra. Next, $\mathrm{He}$ and $\mathrm{N}_{2}$ spectra were separately measured for one minute each to calculate the mirror reflectivity of the BBCES channels, as described below. Next, aerosol samples were generated, and pulled through the flow system using the CPC. $\mathrm{N}_{2}$ spectra were recorded regularly, usually after three or four different aerosol sizes were measured. Each aerosol and $\mathrm{N}_{2}$ measurement reported is an average of 150 spectra integrated for $0.4 \mathrm{~s}$ each, for a total integration time of $1 \mathrm{~min}$. The reflectivity measurement and calculation was typically repeated hourly.

\section{Data analysis}

\subsection{Determination of aerosol optical extinction from BBCES}

The expression for the optical extinction in the BBCES cavities may be derived using either an infinite sum for the light transmission through the cavity (Fiedler et al., 2003) or a differential equation for light input and output (Washenfelder et al., 2008). These two approaches give an equivalent, general expression that relates the optical extinction, $\alpha(\lambda)$, to the observed change in transmitted light intensity through the cavity as

$\alpha(\lambda)=\left(\frac{1-R(\lambda)}{d}\right)\left(\frac{I_{0}(\lambda)-I(\lambda)}{I(\lambda)}\right)$

where $\lambda$ is the wavelength of light, $d$ is the cavity length, $R(\lambda)$ is the mirror reflectivity, $I_{0}(\lambda)$ is the reference spectrum (an empty cavity for the expression above), and $I(\lambda)$ is the measured spectrum at each wavelength. For our experimental conditions, we more conveniently define $I_{0}(\lambda)$ as a spectrum of $\mathrm{N}_{2}$ and explicitly account for its Rayleigh scattering. Additionally, for aerosol measurements, we also account for the portion of the cell volume that is occupied by mirror purge flow. We define the ratio of the total cell length to the sample cell length as $R_{\mathrm{L}}$. Incorporating these changes, we derive the expression

$\alpha(\lambda)=R_{\mathrm{L}}\left(\frac{(1-R(\lambda))}{d}+\alpha_{\text {Rayleigh } \mathrm{N}_{2}}(\lambda)\right)\left(\frac{I_{\mathrm{N}_{2}}(\lambda)-I(\lambda)}{I(\lambda)}\right)$ where $I_{\mathrm{N}_{2}}(\lambda)$ is the spectrum of $\mathrm{N}_{2}$ and $\alpha_{\text {Rayleigh } \mathrm{N}_{2}}(\lambda)$ is the extinction due to Rayleigh scattering by $\mathrm{N}_{2}$.

For the aerosol measurements, $R_{\mathrm{L}}$ may either be measured using a known extinction, such as a dilute concentration of $\mathrm{NO}_{2}$, or defined geometrically from the assumption that aerosols follow the gas flow path and are not present in the purge volumes. In this analysis, we used $R_{\mathrm{L}}$ values measured from the optical extinction of $\sim 70 \mathrm{ppbv}$ of $\mathrm{NO}_{2}$ with and without the mirror purges (i.e., with $70 \mathrm{ppbv}$ of $\mathrm{NO}_{2}$ filling only the central portion of the cell, or its entire length).

In order to use Eq. (2), it is necessary to first determine $R(\lambda)$. Mirror reflectivity (or effective cavity extinction, defined as $(1-R(\lambda)) / d$ ) can be determined by introducing a known extinction into the cavity. Rayleigh extinction is useful for this calculation because it varies slowly with wavelength in a well-defined manner across the entire region of interest, and requires only measurements of temperature and pressure. In this work, we calculated $R(\lambda)$ using Rayleigh scattering cross sections for $\mathrm{N}_{2}$ fitted to Bodhaine et al. (1999) data $\left(\sigma_{\text {Rayleigh } \mathrm{N}_{2}}=1.2577 \times 10^{-15} \times\right.$ $\lambda^{-4.1814}$ ) and He fitted to Shardanand and Rao (1977) data $\left(\sigma_{\text {Rayleigh He }}=1.336 \times 10^{-17} \times \lambda^{-4.1287}\right)$.

\subsection{Determination of aerosol optical cross section from BBCES}

For the cavity containing only particles in $\mathrm{N}_{2}$ gas, the relationship between aerosol optical cross section and aerosol optical extinction is equal to

$\sigma\left(\lambda, D_{p}, m\right)=\frac{\alpha\left(\lambda, D_{p}, m\right)}{N\left(D_{p}\right)}$

where $\alpha\left(\lambda, D_{p}, m\right)$ is the aerosol extinction and $N\left(D_{p}\right)$ is the aerosol number density.

The aerosol cross section in Eq. (3) is a function of the wavelength of incident radiation $(\lambda)$, the diameter of the particle $\left(D_{p}\right)$, and the complex refractive index $(m)$. The complex refractive index, $m$, for a particle relative to the surrounding medium is further described as

$m(\lambda)=n(\lambda)+k(\lambda) i$

where the real part, $n$, represents the scattering component and the imaginary part, $k$, represents the absorbing component. Particles with $k=0$ are purely scattering, while particles with $k>\sim 0.25$ are typically described as strongly absorbing. Slightly absorbing particles fall between these two extremes. The generalized expression for $\sigma$ is

$\sigma=f\left(\lambda, D_{p}, n, k\right)$.

\subsection{Determination of the complex refractive index from BBCES}

The simplified expression for $\sigma$ in Eq. (5) conceals a complex dependence on the variables $\lambda, D_{p}, n$, and $k$. However, for 
given values of $\lambda, D_{p}, n$, and $k$ and particles that are assumed to be spherical, Eq. (5) may be readily solved using numerical codes to determine the optical cross section (Bohren and Huffman, 1983) as demonstrated previously (Pettersson et al., 2004; Lack et al., 2006; Abo Riziq et al., 2007; Flores et al., 2009, 2012; Lang-Yona et al., 2009; Nakayama et al., 2010; Miles et al., 2010; Chartier and Greenslade, 2012; Bluvshtein et al., 2012).

The goal of this work is to determine $n$ and $k$ for different aerosol types by measuring the wavelength dependence of $\sigma$ for particles of known $N$ and $D_{p}$. As Eq. (5) indicates, $n$ and $k$ can be determined using two approaches: (1) for particles with a slight spectral dependence of the refractive index (e.g. PSL, ammonium sulfate), measurement of a single diameter or size distribution at multiple wavelengths can be used to determine $n$ and $k$; (2) for aerosols with substantial spectral dependence of the refractive index (e.g. Suwannee River fulvic acid), measurement of multiple diameters can be used to determine $n$ and $k$ for each wavelength. This is similar to the approach used in conventional CRDS measurements (Pettersson et al., 2004; Abo Riziq et al., 2007; Flores et al., 2012), although used for multiple wavelengths in this case. The implementation of these approaches is described in further detail below.

\subsubsection{Determination of the complex refractive index for monodisperse aerosols neglecting spectral dependence}

For particles whose refractive index does not vary strongly with wavelength over the selected wavelength region, the extinction cross section given in Eq. (5) is a function of only $D_{p}, n$, and $k$. The refractive index may therefore be retrieved from the extinction cross section measured at multiple wavelengths for a single particle diameter. We apply this retrieval to monodisperse aerosol (PSL) and aerosol whose refractive index is sufficiently well-known to correct for multiplecharged particles (e.g. ammonium sulfate).

In this approach, the measured extinction cross section for each diameter is compared to values calculated from Mie theory. The real and imaginary components of the complex refractive index for the calculated cross section are varied to minimize the expression:

$\chi^{2}=\sum_{i=1}^{N_{\lambda}} \frac{\left(\sigma_{\text {measured }}-\sigma_{\text {calculated }}\right)_{i}^{2}}{\varepsilon_{i}^{2}}$,

where $\varepsilon$ is the estimated error in the individual measurement and $N_{\lambda}$ is the number of wavelengths. The uncertainties are calculated from the deviation of $\chi^{2}$ in the vicinity of the minimum. Assuming the errors of the measurement to be normally distributed, the values of $\chi^{2}$ for different measurements follow a $\chi^{2}$ distribution for the two degrees of freedom $n$ and $k$. The quantile for the $1 \sigma(68.3 \%)$ confidence level for this parameter set is 2.298 . Any measurement that falls within the $1 \sigma$ error bound of the best measurement is considered acceptable if $\chi^{2}<\chi_{\min }^{2}+2.298$ (Spindler et al., 2007; Dinar et al., 2008).

\subsubsection{Determination of complex refractive index as a function of wavelength for polydisperse aerosol}

A more general approach to retrieve the complex refractive index uses multiple aerosol diameters and does not assume that $n$ and $k$ are invariant with wavelength. In this case, $\sigma\left(\lambda, D_{p}, n, k\right)$ is determined from $\alpha\left(\lambda, D_{p}, n, k\right) / N\left(D_{p}\right)$. PSL have narrow, monodisperse size distributions, and $N\left(D_{p}\right)$ may be accurately represented as a single value, $N$. In contrast, an aerosol produced from liquid solution (or sampled from the ambient atmosphere) and classified with a DMA has a broader and multi-peaked population that consists of singly, doubly, and triply charged particles, each having a finite dispersion. The larger multiplecharged particles will generally have a greater extinction cross section than the population of singly charged particles, leading to an overestimation of the extinction cross section for the selected, primary diameter. Multiple-charged particles transmitted through the DMA make a significant contribution to the measured cross section, and must be correctly accounted for. For example, with an ammonium sulfate solute concentration of $2.0 \mathrm{~g} \mathrm{~L}^{-1}$ and a DMA size selection of $200 \mathrm{~nm}$, the size distribution includes $71 \%$ singly charged particles $\left(D_{p}=200 \mathrm{~nm}\right), 23 \%$ doubly charged particles $\left(D_{p}=315 \mathrm{~nm}\right)$, and $6 \%$ triply charged particles $\left(D_{p}=421 \mathrm{~nm}\right)$. In addition, the optical cross sections of the multiple-charged particles are typically greater than that of the singly charged particles, with a fractional contribution to the optical cross section that is greater than their fractional abundance.

A common method used in CRDS retrievals of complex refractive index is to calculate and subtract the extinction due to doubly and triply charged particles from the total measured extinction (Fierz-Schmidhauser et al., 2010; Cappa et al., 2011; Flores et al., 2012). The disadvantage of this method is that it requires an assumed refractive index for the multiple-charged particles. To avoid this, we used the full aerosol size distribution to determine the best fit $n$ and $k$ values. We measured the aerosol size distribution atomized for each solute concentration from $D_{p}=80-1850 \mathrm{~nm}$ using scanning electrical mobility spectroscopy (Wang and Flagan (1990) using Markowski's (1987) version of the Twomey (1975) algorithm). We then used DMA transfer theory (Knutson and Whitby, 1975) with Wiedensohler's (1988) steady-state charge distribution approximation (with subsequent erratum) to quantify the full size distribution of singly, doubly, and triply charged particles exiting the DMA for each primary diameter setting. This approach assumes that the multiple-charged particles have a refractive index identical to that of the singly charged particles, which was true for these laboratory experiments. 
For each cross section measurement, we calculated "effective" Mie cross sections as a function of $n$ and $k$ corresponding to the measured size distribution. The best fit values of $n$ and $k$ are determined by minimizing the difference between $\sigma_{\text {measured }}$ and $\sigma_{\text {calculated }}$. This method requires measurements for at least two different diameter setpoints, because a single measurement of $\sigma\left(\lambda, D_{p}, n, k\right)$ for one wavelength and one aerosol size distribution represents one equation and two unknowns $(n$ and $k$ ). The solution is determined by measuring the cross section for multiple diameter setpoints and minimizing the expression:

$\chi^{2}=\sum_{i=1}^{N_{D_{p}}}\left(\frac{\sigma_{\text {measured }}-\sigma_{\text {calculated }}}{\sigma_{\text {measured }}}\right)_{i}^{2}$.

This expression appears similar to Eq. (6) but represents a separate, independent calculation for each wavelength element. We determine the absolute uncertainty in the retrieved $n$ and $k$ empirically by varying $\sigma_{\text {measured }}$ by the uncertainty of the measurement ( $\pm 4.1 \%$ as described in Sect. 3.4).

\subsection{Precision and accuracy of the optical extinction cross sections and refractive indices}

The precision of the $\alpha\left(\lambda, D_{p}, m\right)$ measurement is $0.21 \mathrm{Mm}^{-1}$ and $0.17 \mathrm{Mm}^{-1}\left(1 \mathrm{Mm}^{-1}=10^{-8} \mathrm{~cm}^{-1}\right)$ for $1 \mathrm{~min}$ BBCES measurements at the center wavelengths of $365 \mathrm{~nm}$ and $405 \mathrm{~nm}$. This precision is limited by noise in the spectra, as the system is shot-noise limited at the CCD detector. The precision of the $\sigma\left(\lambda, D_{p}, m\right)$ value additionally includes the sampling statistics of the aerosol in the optical beam, although this makes a minor contribution. This is an important difference between the BBCES and CRDS, because the broadband beam has a much greater diameter than a laser, and thus intersects a larger sample volume (see discussion of CRDS in Pettersson et al., 2004; Baynard et al., 2007).

The absolute accuracy of the $\sigma\left(\lambda, D_{p}, m\right)$ cross section values is limited by the uncertainty in the Rayleigh scattering cross sections for $\mathrm{N}_{2}$ and $\mathrm{He}$, sample pressure and temperature, total flow, individual mirror purge flows, $R_{\mathrm{L}}$, particle concentration, particle size distribution, and particle losses in the cavities. The uncertainty in the Rayleigh scattering cross sections of $\mathrm{N}_{2}$ is $\pm 2 \%$. Although the uncertainty in the Rayleigh scattering cross section for $\mathrm{He}$ is similar, its cross section is small and makes a minor contribution to the total uncertainty. The uncertainty in the sample pressure is $\pm 0.3 \%$ as determined by comparison to a $\mathrm{Hg}$ manometer and by confirming that the pressure drop for the three cells is less than $0.5 \mathrm{hPa}$. The uncertainty in the sample temperature is approximately $\pm 0.2 \%$. The uncertainties in the total flow and mirror purge flows contribute to an uncertainty in the sample dilution correction of $0.3 \%, 0.2 \%$, and $0.1 \%$, respectively, for the BBCES $405 \mathrm{~nm}$, BBCES $365 \mathrm{~nm}$, and CRDS, with the largest error for the cell farthest from the $\mathrm{CPC}$ because it requires the greatest flow dilution correction.
We estimate an uncertainty in $R_{\mathrm{L}}$ of $2 \%$, because $R_{\mathrm{L}}$ for aerosol may differ from the value determined using $\mathrm{NO}_{2}$. Particle losses through the system were both measured and modeled, and we estimate a $2 \%$ uncertainty in the particle loss correction. Uncertainty in the particle size distribution is neglected here. The manufacturer's reported uncertainty for the TSI $3022 \mathrm{~A} \mathrm{CPC} \mathrm{is} \pm 10 \%$ for particle concentrations less than $50000 \mathrm{~cm}^{-3}$. However, we estimate the actual uncertainty in particle concentration to be limited by the CPC sample flow rate and digital counting statistics. We calibrated the CPC sample flow rate with an uncertainty of $1 \%$. The uncertainty in the digital counting is expected to follow Poisson statistics, with a $60 \mathrm{~s}$ sample time giving an uncertainty of $1.8 \%$ for 10 particles $\mathrm{cm}^{-3}$ and $0.3 \%$ for 300 particles $\mathrm{cm}^{-3}$ (for a $5.3 \mathrm{~cm}^{3} \mathrm{~s}^{-1}$ detector flow rate). The addition of all uncertainties in quadrature, with the omission of the uncertainty in particle size distribution, gives a total uncertainty of 3.6$4.1 \%$ for the aerosol extinction cross sections.

\section{Results and discussion}

\subsection{Polystyrene latex spheres}

We measured six different diameters of PSL $(199,299$, 404, 499, 596, and $802 \mathrm{~nm}$; see Table 1), with five or more concentration measurements for each diameter, to test the two refractive index retrieval methods described in Sect. 3. These measurements allow us to calculate the extinction cross section for every wavelength in both BBCES channels and for the single wavelength of the CRDS. As Eq. (3) shows, we expect a linear relationship between $\alpha\left(\lambda, D_{p}, m\right)$ and $N\left(D_{p}\right)$, with a slope equal to $\sigma\left(\lambda, D_{p}, m\right)$ (Pettersson et al., 2004; Abo Riziq et al., 2007). For single measurements of $\alpha\left(\lambda, D_{p}, m\right)$ at a given $N\left(D_{p}\right)$, we may determine $\sigma\left(\lambda, D_{p}, m\right)$ from the ratio of $\alpha\left(\lambda, D_{p}, m\right) / N\left(D_{p}\right)$.

Figure 2 shows the determination of $\sigma\left(\lambda, D_{p}, m\right)$ for multiple measurements of $\alpha\left(\lambda, D_{p}, m\right)$ at different $N\left(D_{p}\right)$ for a single wavelength element of the BBCES $(407.025 \mathrm{~nm})$. The CRDS at $407.0 \mathrm{~nm}$ is also plotted, and the BBCES and CRDS cross sections agree within $2 \%$ for $600 \mathrm{~nm}$ diameter particles, and to better than $1 \%$ for smaller particles.

For each of the six PSL diameters, the value of $\sigma$ was determined from the slope for each wavelength element of the BBCES 360-390 and 385-420 nm channels. The resulting $\sigma$ values are plotted in Fig. 3, together with the CRDS value at $407.0 \mathrm{~nm}$. The agreement at $407 \mathrm{~nm}$ between the CRDS and BBCES measurements in Fig. 3a is an important validation of the BBCES measurements. Furthermore, there is agreement between the two independent BBCES instruments in the region from $385-390 \mathrm{~nm}$ where they overlap spectrally, with a maximum difference in $\sigma$ of $2.6 \%$. 


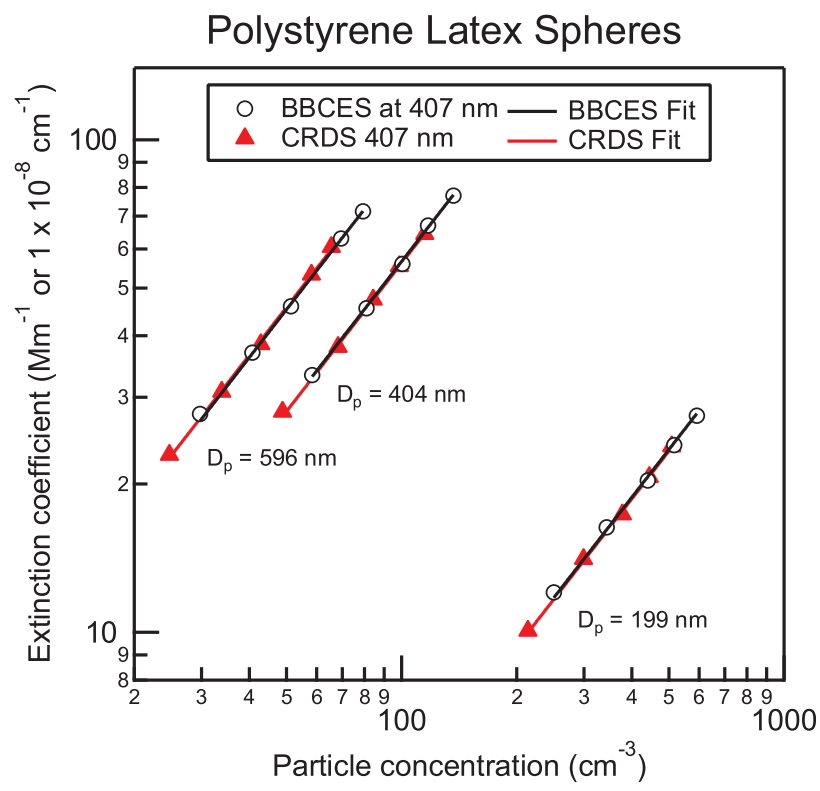

Fig. 2. Extinction coefficients as a function of particle concentration for polystyrene latex spheres (PSL) at 199, 404, and $596 \mathrm{~nm}$ diameters. CRDS measurements at $\lambda=407 \mathrm{~nm}$ (red triangles) are shown together with the measurements from a single wavelength element $(\lambda=407.025 \mathrm{~nm})$ of the BBCES (black circles). The extinction cross sections calculated from linear fits to each diameter are $\sigma_{\mathrm{CRDS}}=4.73$ $( \pm 0.05) \times 10^{-10} \mathrm{~cm}^{2}$ and $\sigma_{\text {BBCES }}=4.70( \pm 0.02) \times 10^{-10} \mathrm{~cm}^{2}$ at $D_{p}=199 \mathrm{~nm} ; \sigma_{\mathrm{CRDS}}=5.68( \pm 0.04) \times 10^{-9} \mathrm{~cm}^{2}$ and $\sigma_{\mathrm{BBCES}}=$ $5.66( \pm 0.01) \times 10^{-9} \mathrm{~cm}^{2}$ at $D_{p}=404 \mathrm{~nm} ;$ and $\sigma_{\mathrm{CRDS}}=9.26$ $( \pm 0.07) \times 10^{-9} \mathrm{~cm}^{2}$ and $\sigma_{\mathrm{BBCES}}=9.05( \pm 0.03) \times 10^{-9} \mathrm{~cm}^{2}$ at $D_{p}=596 \mathrm{~nm}$.

\subsubsection{Determination of complex refractive index for PSL neglecting spectral dependence}

Refractive indices were retrieved from extinction cross sections for each PSL diameter using the method described in Sect. 3.3.1. This analysis was independently performed for PSL cross section measurements by each of the two BBCES channels, and for their combined spectral range from 360 to $420 \mathrm{~nm}$ (Fig. 3a). The results are summarized in Table 1, which shows consistency in the complex RI retrieved for different PSL sizes. The complex RI for the PSL describes an aerosol that is strongly scattering, with an absorbing component that is not significantly different from zero. As a result, the fits in Fig. 3a clearly show Mie resonances for the different particle sizes, and these are more visible for the expanded cross sections shown in Fig. 3b and c for 299 and 802 nm diameter particles.

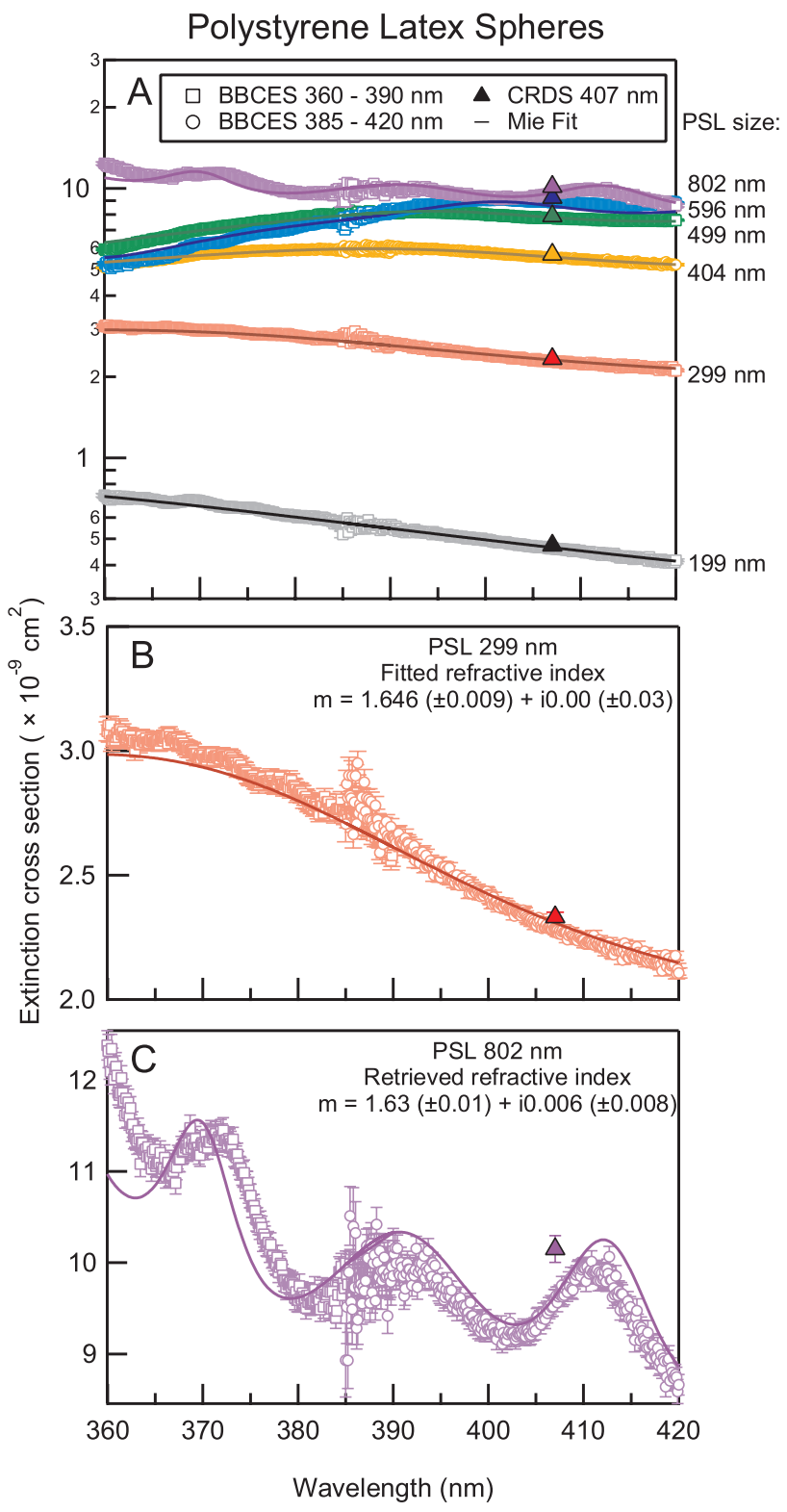

Fig. 3. (a) Extinction cross sections as a function of wavelength for 199-802 nm diameter PSL measured with the BBCES 360-390 nm (squares), BBCES $385-420 \mathrm{~nm}$ (circles), and CRDS at $\lambda=407 \mathrm{~nm}$ (triangles). The solid lines show the best Mie fit. (b) Expanded view of the $299 \mathrm{~nm}$ PSL extinction cross section measurements and Mie fit. The retrieved complex refractive index is given in the upper right hand corner. (c) Similar expanded view for $802 \mathrm{~nm}$ PSL.

\subsubsection{Determination of complex refractive index for PSL as a function of wavelength}

The complex RI was also determined using the full retrieval (described in Sect. 3.3.2), which combines measurements made at several particle diameters and allows $n$ and $k$ to vary with wavelength. For the calculations, we assumed a Gaussian size distribution with center diameter and standard 
Table 1. Complex refractive index determined for polystyrene latex spheres using two methods.

\begin{tabular}{llll}
\hline \multicolumn{3}{c}{ Retrieval with no wavelength dependence } \\
\hline Diameter $(\mathrm{nm})$ & $360-390 \mathrm{~nm}$ & $385-420 \mathrm{~nm}$ & $360-420 \mathrm{~nm}(\mathrm{combined})$ \\
\hline $199 \pm 6$ & $1.656( \pm 0.01)+0.0( \pm 0.04) i$ & $1.652( \pm 0.007)+0.0( \pm 0.011) i$ & $1.653( \pm 0.008)+0.0( \pm 0.014) i$ \\
$299 \pm 6$ & $1.653( \pm 0.012)+0.0( \pm 0.014) i$ & $1.644( \pm 0.008)+0.0( \pm 0.068) i$ & $1.646( \pm 0.009)+0.0( \pm 0.029) i$ \\
$404 \pm 4$ & $1.651( \pm 0.029)+0.008( \pm 0.009) i$ & $1.641( \pm 0.011)+0.003( \pm 0.009) i$ & $1.647( \pm 0.015)+0.008( \pm 0.009) i$ \\
$499 \pm 5$ & $1.642( \pm 0.006)+0.0( \pm 0.013) i$ & $1.624( \pm 0.029)+0.007( \pm 0.008) i$ & $1.639( \pm 0.009)+0.004( \pm 0.009) i$ \\
$596 \pm 6$ & $1.651( \pm 0.005)+0.0( \pm 0.011) i$ & $1.624( \pm 0.009)+0.016( \pm 0.015) i$ & $1.644( \pm 0.010)+0.0( \pm 0.011) i$ \\
$802 \pm 6$ & $1.643( \pm 0.01)+0.007( \pm 0.009) i$ & $1.628( \pm 0.011)+0.004( \pm 0.006) i$ & $1.634( \pm 0.012)+0.006( \pm 0.008) i$ \\
\hline
\end{tabular}

Table 1. Continued.

\begin{tabular}{ll}
\hline \multicolumn{2}{c}{ Retrieval with wavelength dependence } \\
\hline Wavelength $(\mathrm{nm})$ \\
\hline 360 & $1.651( \pm 0.002)+0.000( \pm 0.001) i$ \\
370 & $1.653( \pm 0.002)+0.003( \pm 0.003) i$ \\
380 & $1.643( \pm 0.002)+0.000( \pm 0.001) i$ \\
390 & $1.639( \pm 0.004)+0.006( \pm 0.004) i$ \\
400 & $1.63( \pm 0.01)+0.001( \pm 0.001) i$ \\
410 & $1.63( \pm 0.01)+0.007( \pm 0.002) i$ \\
420 & $1.633( \pm 0.005)+0.000( \pm 0.005) i$ \\
\hline
\end{tabular}

deviation given by the PSL manufacturer. DMA-classified PSL particles are nearly monodisperse, without multiplecharged particles.

The results for the retrievals of PSL refractive index as a function of wavelength are shown in Table 1 and Fig. 4. The error bars in Fig. 4 were calculated by scaling the measured extinction cross section by an uncertainty of $\pm 4.1 \%$. The real part of the refractive index (Fig. 4a) is $n=1.657( \pm 0.002)$ (Table 1) at $360 \mathrm{~nm}$, and decreases to $1.637( \pm 0.005)$ at $420 \mathrm{~nm}$. The imaginary part of the refractive index (Fig. 4b) does not differ significantly from zero across the measured spectral region, with the exception of retrieved values reaching $0.011( \pm 0.01)$ at $410 \mathrm{~nm}$.

\subsubsection{Comparison of PSL refractive index to published values}

Polystyrene latex spheres are widely used to calibrate optical aerosol instruments. Refractive indices have been reported for bulk samples (Matheson and Saunderson, 1952; Nikolov and Ivanov, 2000; Sultanova et al., 2003), particles in suspension (Bateman et al., 1959; Smart and Willis, 1967; Ma et al., 2003; French et al., 2007), and aerosol particles (Pettersson et al., 2004; Abo Riziq et al., 2007; Baynard et al., 2007; Lang-Yona et al., 2009; Chartier and Greenslade, 2012). These measurements are nicely summarized by Miles et al. (2010), with the exception of the more recent Chartier and Greenslade (2012) result.
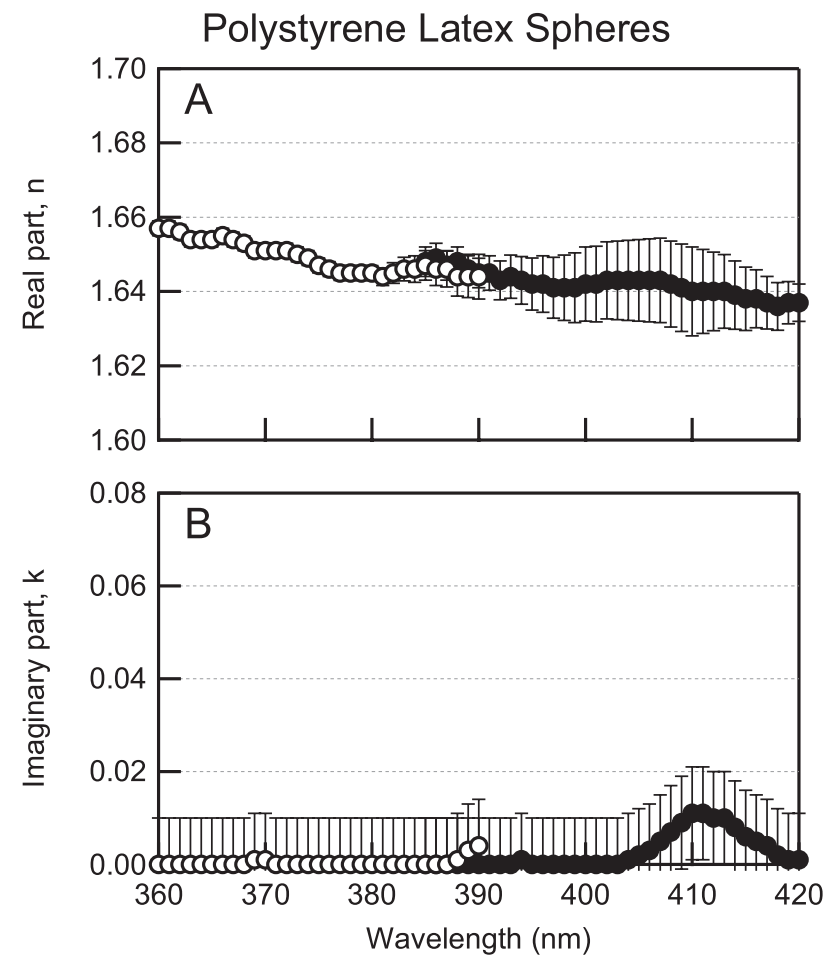

Fig. 4. (a) The real part of the complex refractive index (RI) as a function of wavelength for the BBCES 360-390 nm (open circles) and the BBCES $385-420 \mathrm{~nm}$ (filled circles). (b) The imaginary part of the RI.

Only two prior studies have reported the complex refractive index of PSL particles at ultraviolet wavelengths. Baynard et al. (2007) measured four PSL diameters using a pulsed CRDS system at $\lambda=355 \mathrm{~nm}$. The authors reported an agreement of $5 \%$ with the refractive index values in Nikolov and Ivanov (2000), but did not independently retrieve an RI. Chartier and Greenslade (2012) measured refractive indices at $\lambda=248$ and $335 \mathrm{~nm}$. To our knowledge, ours is the first study to measure the refractive index for PSL as a function of wavelength between $\lambda=360-420 \mathrm{~nm}$.

As shown in Table 1 and Fig. 4, the BBCES measurements give a real part of the refractive index of $n=1.64-1.66$ 
at $\lambda=360-420 \mathrm{~nm}$, increasing with decreasing wavelength. The studies of bulk and suspended polystyrene summarized by Miles et al. (2010) also indicate that the real part of the refractive index increases slightly with decreasing wavelength, with a value of $n=1.60-1.62$ at $400 \mathrm{~nm}$. These values are lower than the retrieved values reported here. However, the values reported here are more consistent with Chartier and Greenslade (2012), who recently measured a real part of the refractive index $n=1.81( \pm 0.03)$ at $\lambda=248 \mathrm{~nm}$ and $n=$ $1.72( \pm 0.02)$ at $\lambda=335 \mathrm{~nm}$, which is greater than the results reported for particles in suspension by French et al. (2007) and Ma et al. (2003).

As shown in Table 1 and Fig. 4, the BBCES measurements give an imaginary part of the refractive index that is not significantly different from zero at $\lambda=360-404$, but show an increase to $k=0.01$ centered at $410 \mathrm{~nm}$. Chartier and Greenslade (2012) reported values of $k=0.05$ and 0.005 for PSL aerosol at $\lambda=248 \mathrm{~nm}$ and $\lambda=355 \mathrm{~nm}$, respectively. Studies of PSL aerosol at $\lambda=532 \mathrm{~nm}$ have reported imaginary components of $k=0.01$ and $k=0.0$ (Abo Riziq et al., 2007; Lang-Yona et al., 2009). Overall, our $n$ and $k$ values are consistent with the prior literature values.

\subsection{Ammonium sulfate aerosol}

To test the performance of the BBCES with broader size distributions and an atmospherically-relevant purely scattering substance, we measured ammonium sulfate (AS) at DMA diameter setpoints from 200 to $700 \mathrm{~nm}$ in $50 \mathrm{~nm}$ steps. The extinction cross section (corrected for multiple-charged particles; see next section) for all the measured sizes for both BBCES and the CRDS at $407 \mathrm{~nm}$ are shown in Fig. 5. The open squares and circles show the results for the BBCES at 360-390 $\mathrm{nm}$ and 385-420 nm, respectively. The CRDS measurements are shown as open triangles. Figure 5 shows agreement in the overlap region of the two BBCES channels, and for the BBCES and CRDS at $\lambda=407 \mathrm{~nm}$.

\subsubsection{Determination of complex refractive index for ammonium sulfate neglecting spectral dependence}

Using the wavelength-independent approach (Sect. 3.3.1), we retrieved the complex refractive index from extinction measurements shown in Fig. 5. This method is only appropriate for a monodisperse size distribution, and required that we correct the measured optical extinction for multiple-charged particles. The assumed refractive index used for the subtraction of extinction due to multiple-charged particles was $1.52+0 i$ (Abo Riziq et al., 2008), with no wavelength dependence. The refractive index was independently determined for 13 aerosol diameters from $200-800 \mathrm{~nm}$, with an average value of $1.51( \pm 0.01)+0.02( \pm 0.01) i$

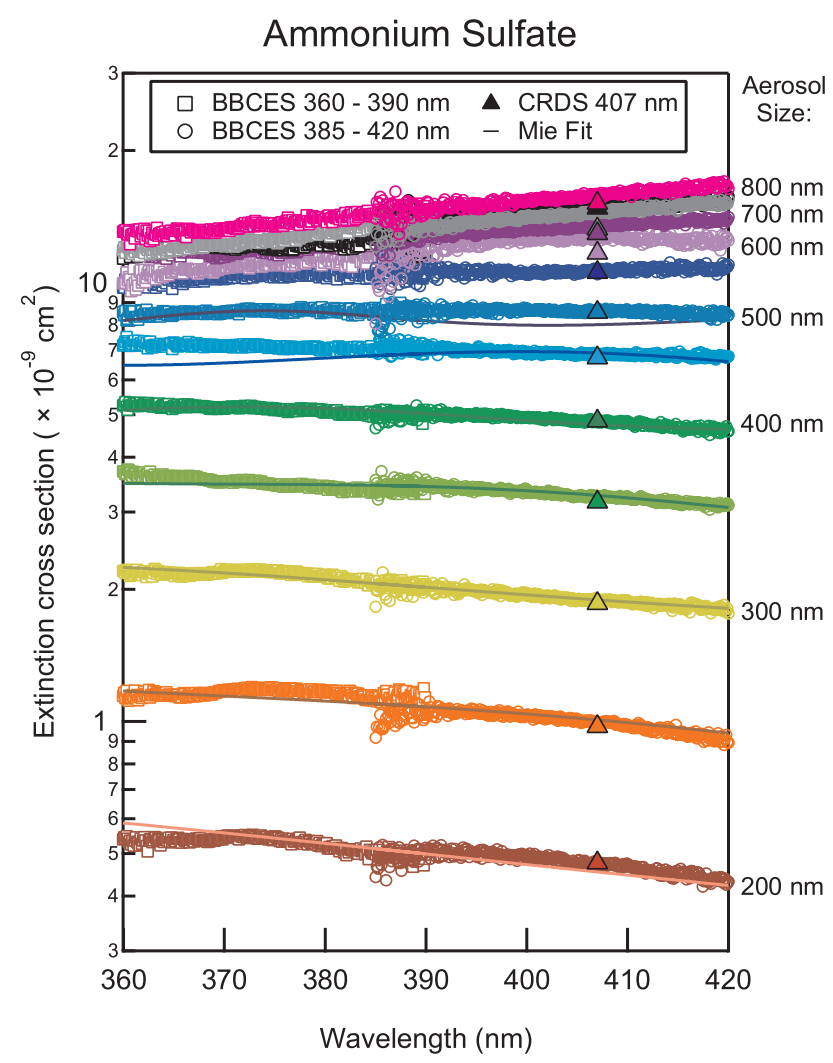

Fig. 5. Extinction cross sections as a function of wavelength for ammonium sulfate aerosol at $200-800 \mathrm{~nm}$ diameter measured with the BBCES 360-390 nm, BBCES 385-420 nm, and CRDS at $\lambda=$ $407 \mathrm{~nm}$. The solid lines show the best Mie fit. The extinction cross sections shown in this plot have been corrected for doubly and triply charged particles, using an assumed refractive index of $m=1.52+$ $0 i$.

\subsubsection{Determination of complex refractive index for ammonium sulfate as a function of wavelength}

Results from the full retrieval of complex refractive indices as a function of wavelength, derived using the full size distribution, are shown in Fig. 6 for the two BBCES channels. This method requires no assumption for the refractive index of the multiple-charged particles. The retrieval gives a value of $n=1.513( \pm 0.004)$ at $360 \mathrm{~nm}$, which increases to $n=1.540$ $( \pm 0.007)$ at $420 \mathrm{~nm}$. The retrieved imaginary part of the refractive index is $0.000( \pm 0.001)$ for all wavelengths.

\subsubsection{Comparison of ammonium sulfate refractive index to published values}

Aerosols containing ammonium sulfate are some of the most abundant in the troposphere, and have a significant contribution to Earth's radiative budget (IPCC, 2007). Hence, the optical properties of AS are important to atmospheric radiative transfer models and to calculations of climatic 

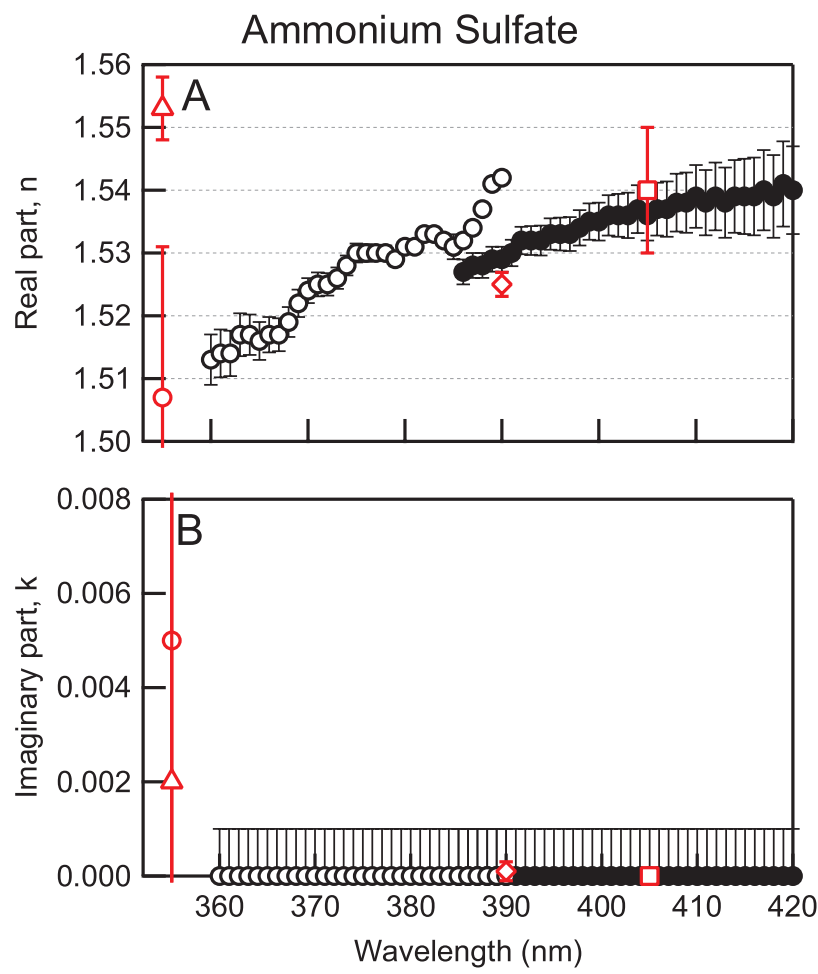

Fig. 6. (a) The real part of the complex refractive index (RI) as a function of wavelength for each wavelength from the BBCES for ammonium sulfate aerosol. Red markers show values reported by Trainic et al. (2011, triangle), Flores et al. (2012, circle), Dinar et al. (2008, diamond), and Toon et al. (1976, square). (b) Similarly, the imaginary part of the RI.

forcing. CRDS studies have retrieved complex RI values at $\lambda=532 \mathrm{~nm}$ with values for the real component between $n=1.51-1.53$ and an imaginary component of $k=0$ (Abo Riziq et al., 2007; Spindler et al., 2007; Lang-Yona et al., 2009; Flores et al., 2009). There are few measurements in the near UV region of the complex refractive index of AS, and the relevant values are all included in Fig. 6. At $355 \mathrm{~nm}$, Flores et al. (2012) and Trainic et al. (2011) reported values of $m=1.507( \pm 0.024)+0.005( \pm 0.025) i$, and $m=1.553( \pm 0.005)+0.002( \pm 0.013) i$, respectively. At $390 \mathrm{~nm}$, Dinar et al. (2008) reported a value of $m=1.525$ $( \pm 0.002)+0.0001( \pm 0.0002) i$. At $405 \mathrm{~nm}$, Toon et al. (1976) reported a real value of $n=1.53-1.55$ and an imaginary value of $k<1 \times 10^{-7}$ determined from the reflectivity and transmission of crystalline ammonium sulfate samples. Our results are consistent with these prior measurements, with the exception of Trainic et al. (2011), as shown in Fig. 6.

\subsection{Nigrosin aerosol}

Nigrosin aerosol is an organic black dye that is commonly used as a model for absorbing particles. We measured extinction by nigrosin particles at DMA diameter setpoints from 200 to $700 \mathrm{~nm}$ in $50 \mathrm{~nm}$ steps. Extinction cross sections for measured sizes between 200 and $500 \mathrm{~nm}$ from both BBCES and the CRDS at $407 \mathrm{~nm}$ are shown in Fig. 7 and used in the refractive index retrievals. At larger diameters, fewer nigrosin particles were generated and accurately quantifying the fraction of triply charged particles with the DMA was difficult. Unlike the ammonium sulfate cross sections shown in Fig. 5, the plotted nigrosin cross sections have not been corrected for doubly and triply charged particles. This is because there are few reported values for the refractive index of nigrosin in the ultraviolet and near-visible spectral regions which would allow the contribution of doubly and triply charged particles to be calculated and subtracted (see Sect. 4.3.3 for a summary of published values). Instead, Fig. 7 shows the size-distribution-weighted cross sections for each DMA diameter setpoint, calculated from $\alpha\left(\lambda, D_{p}, n, k\right) / N$.

\subsubsection{Determination of complex refractive index for nigrosin as a function of wavelength}

A wavelength-independent retrieval is not appropriate for nigrosin, because the spectral dependence of its refractive index for particles is poorly known and the absorbance of its bulk solution varies strongly with wavelength. Refractive index values determined using the full measured particle size distribution are shown in Fig. 8a and b. The retrieval gives a value of $n=1.78( \pm 0.03)$ at $360 \mathrm{~nm}$, which decreases to $n=1.63( \pm 0.03)$ at $420 \mathrm{~nm}$. The imaginary part of the refractive index is $k=0.19( \pm 0.08)$ at $360 \mathrm{~nm}$, and $k=0.21( \pm 0.05)$ at $420 \mathrm{~nm}$, with no wavelength dependence detectable within the measurement precision.

\subsubsection{Comparison of nigrosin refractive index to published values and UV-visible absorption spectra}

Prior studies have reported the refractive index for nigrosin aerosol in the visible spectral region (Garvey and Pinnick, 1983; Lack et al., 2006; Flores et al., 2009; Lang-Yona et al., 2009; Bluvshtein et al., 2012). The reported values are generally consistent: $1.67+0.26 i$ at $633 \mathrm{~nm}$ (Garvey and Pinnick, 1983); $1.70( \pm 0.04)+0.31( \pm 0.05) i$ at $532 \mathrm{~nm}$ (Lack et al., 2006); $1.649( \pm 0.007)+0.238( \pm 0.008) i$ at $532 \mathrm{~nm}$ (Dinar et al., 2008); $1.72( \pm 0.01)+0.28( \pm 0.08) i$ and $1.65( \pm 0.01)+0.24( \pm 0.01) i$ at $532 \mathrm{~nm}$ (Lang-Yona et al., 2009); and $1.64( \pm 0.04)+0.20( \pm 0.03) i$ for a white light source at 370-780 nm (Flores et al., 2009). No trend with wavelength is evident from the reported data. Although no refractive index values have been reported in the blue or ultraviolet spectral regions, the $n$ and $k$ values reported here for $360-420 \mathrm{~nm}$ are consistent within \pm 0.01 of the values at $532 \mathrm{~nm}$. 


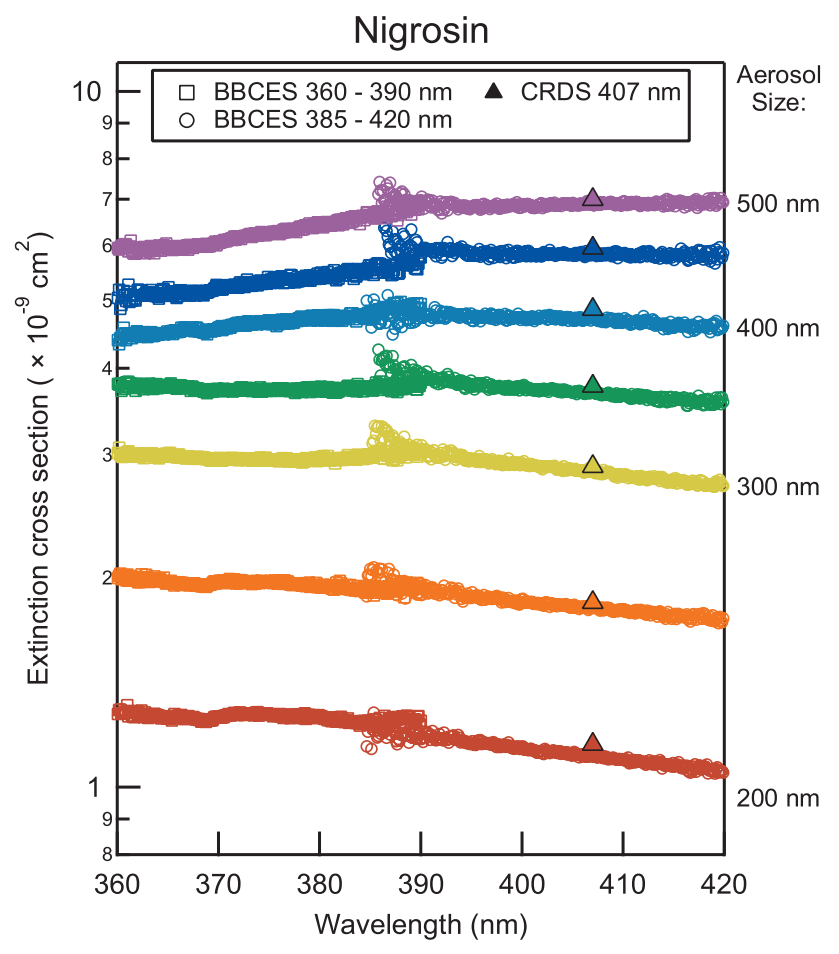

Fig. 7. Extinction cross sections as a function of wavelength for nigrosin aerosol at 200-500 $\mathrm{nm}$ diameter measured with the BBCES $360-390 \mathrm{~nm}$, BBCES $385-420 \mathrm{~nm}$, and CRDS at $\lambda=407 \mathrm{~nm}$. The extinction cross sections shown in this plot have not been corrected for doubly and triply charged particles, because the refractive index of nigrosin as a function of wavelength is not well-known.

\subsection{Suwannee River fulvic acid aerosol}

Suwannee River fulvic acid is a common model for humiclike substances in aged aerosols, and was selected as a surrogate for brown carbon aerosol because it is thought to have strongly wavelength-dependent absorption. We measured extinction by Suwannee River fulvic acid particles at DMA diameter setpoints from 200 to $700 \mathrm{~nm}$ in $50 \mathrm{~nm}$ steps. Extinction cross sections for measured sizes between 200 and $500 \mathrm{~nm}$ from both BBCES and the CRDS at $407 \mathrm{~nm}$ are shown in Fig. 9 and used in the refractive index retrievals. Similarly to the nigrosin cross sections in Fig. 7, the plotted SRFA cross sections have not been corrected for doubly and triply charged particles, as there are few reported values for the refractive index of SRFA in the ultraviolet and nearvisible spectral regions which would allow the contribution of doubly and triply charged particles to be accurately calculated and subtracted, and also because the refractive index for SRFA varies with wavelength (see Sect. 4.4.3 for a summary of published values). Instead, Fig. 9 shows the sizedistribution-weighted cross sections for each DMA diameter setpoint, calculated from $\alpha\left(\lambda, D_{p}, n, k\right) / N$.
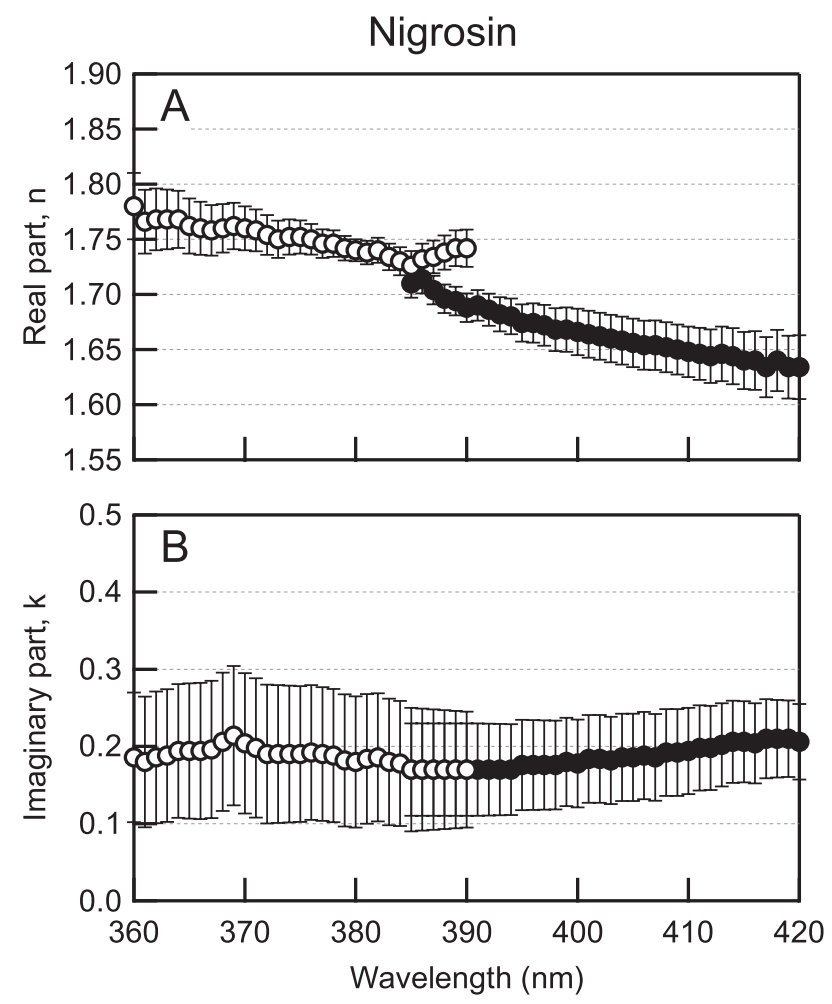

Fig. 8. (a) The real part of the complex refractive index (RI) as a function of wavelength for nigrosin aerosol. (b) The imaginary part of the RI.

\subsubsection{Determination of complex refractive index for Suwannee River fulvic acid as a function of wavelength}

Similar to nigrosin, a wavelength-independent retrieval is not appropriate for SRFA, because its absorption varies as a function of wavelength (Dinar et al., 2008) and is not well known in the ultraviolet spectral region. Refractive index values determined using the full measured particle size distribution are shown in Fig. 10. The retrieval gives a value of $n=1.71( \pm 0.02)$ at $360 \mathrm{~nm}$, which decreases to $1.66( \pm 0.02)$ at $420 \mathrm{~nm}$. The imaginary part of the refractive index is $k=0.07( \pm 0.06)$ at $360 \mathrm{~nm}$, decreasing slightly to a value of $0.06( \pm 0.04)$ at $420 \mathrm{~nm}$.

\subsubsection{Comparison of Suwannee River fulvic acid refractive index to published values}

Prior studies have reported the refractive index for Suwannee River fulvic acid aerosol in the visible spectral region (Dinar et al., 2008; Flores et al., 2009; Lang-Yona et al., 2009). However, it is important to note that different SRFA samples have been supplied by the International Humic Substances Society, and that we have used SRFA 1S101F for this work. For sample 1R101F, Dinar et al. (2008) reports values of $1.602( \pm 0.005)+0.098( \pm 0.005) i$ at $390 \mathrm{~nm}$ 


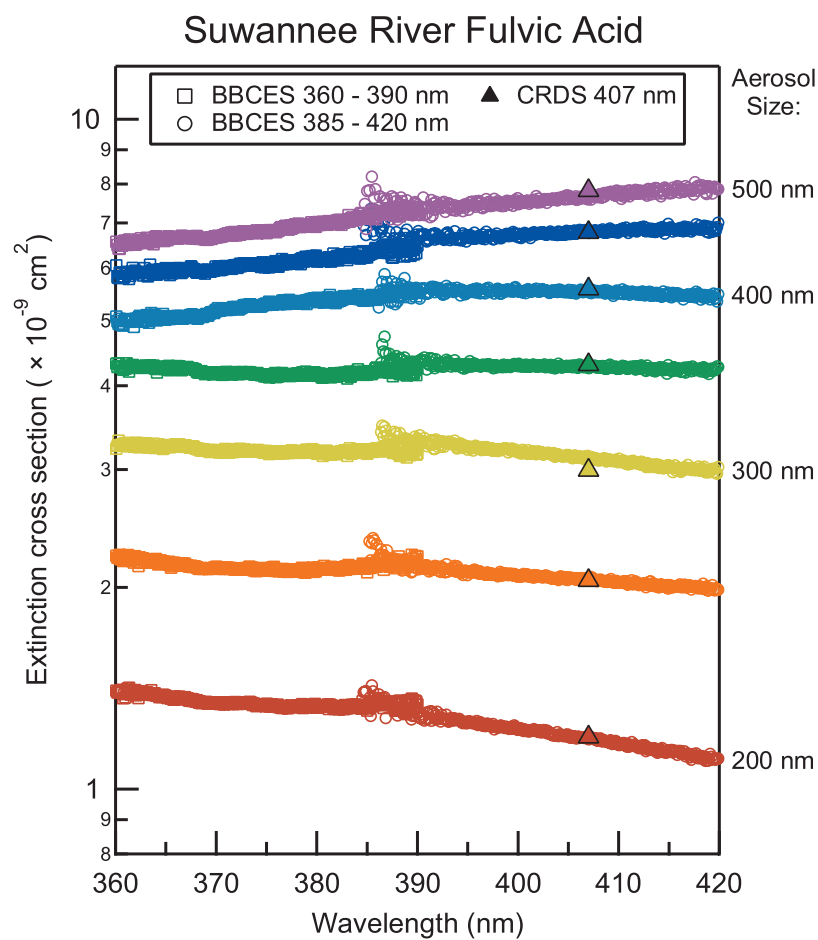

Fig. 9. Extinction cross sections as a function of wavelength for Suwannee River fulvic acid aerosol at $200-500 \mathrm{~nm}$ diameter measured with the BBCES $360-390 \mathrm{~nm}$, BBCES $385-420 \mathrm{~nm}$, and CRDS at $\lambda=407 \mathrm{~nm}$. Similarly to Fig. 7, these cross sections include the population of singly, doubly, and triply charged particles at each DMA setpoint.

and $1.634( \pm 0.004)+0.021( \pm 0.005) i$ at $532 \mathrm{~nm}$. Previous studies have reported $1.520( \pm 0.003)+0.02( \pm 0.01) i$ and $1.65( \pm 0.01)+0.02( \pm 0.01) i$ for cavity ringdown measurements (Lang-Yona et al., 2009) at $532 \mathrm{~nm}$ and 1.53 $( \pm 0.01)+0.0 i$ for a white light source at $370-870 \mathrm{~nm}$ (Flores et al., 2009). Figure 10 shows the only measurement previously reported in the near-ultraviolet spectral region, with a value of $m=1.602( \pm 0.005)+0.098( \pm 0.005) i$ at $390 \mathrm{~nm}$ for SRFA 1R101F (Dinar et al., 2008).

\section{Discussion of uncertainty in retrievals of refractive index}

The error bars for each of the wavelength-dependent retrievals were calculated by scaling the measured extinction cross section by an uncertainty of $\pm 4.1 \%$. However, the resulting error bars differ widely for the four compounds. The uncertainty in $n$ is $0.001-0.002$ for ammonium sulfate, while it is $0.01-0.03$ for nigrosin. For $k$, these uncertainty values are 0.001 and $0.05-0.09$, respectively. Nigrosin has much greater uncertainty in its refractive index because it is a strongly absorbing aerosol and a relatively large change in $k$ for an absorbing aerosol causes only a small change in the aerosol's extinction cross section, making it more difficult to
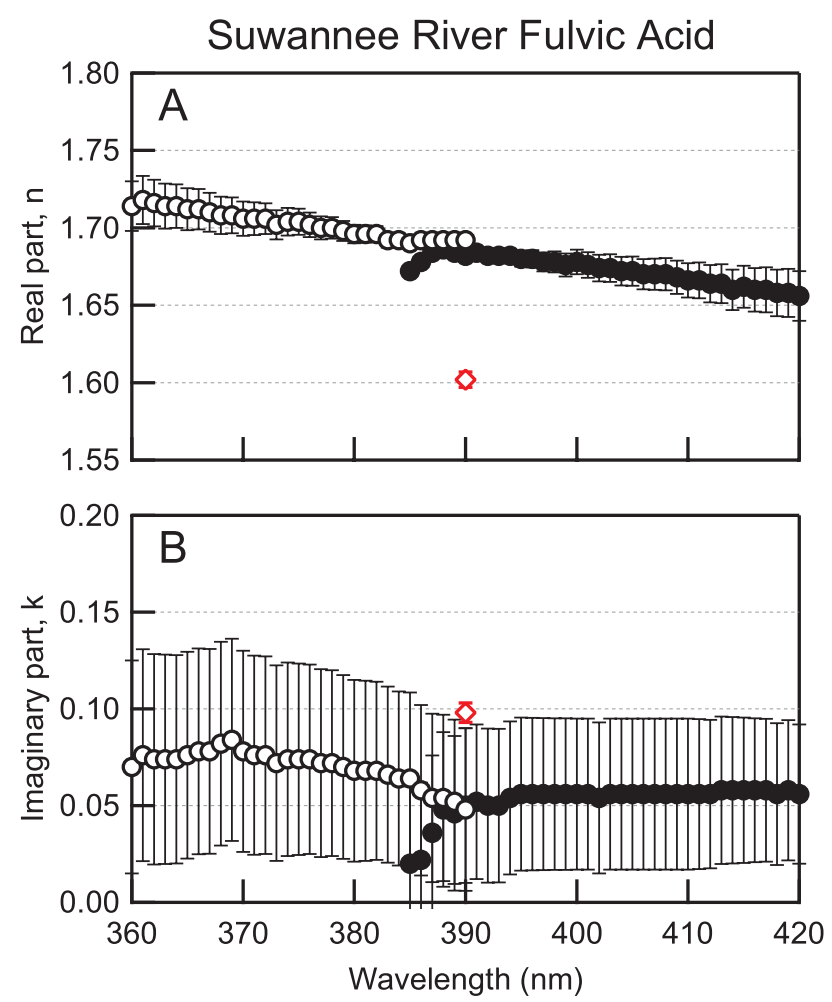

Fig. 10. (a) The real part of the complex refractive index (RI) as a function of wavelength for SRFA aerosol. Red marker shows values reported by Dinar et al. (2008, diamond). (b) Similarly, the imaginary part of the RI.

accurately retrieve the refractive index for absorbing compounds.

The greater difficulty in retrieving refractive indices for absorbing aerosol is demonstrated in Fig. 11, which shows the theoretical refractive indices for a series of purely scattering and strongly absorbing aerosol at three discrete diameters. The three extinction cross sections of the purely scattering aerosol $(m=1.5+0 i, 1.6+0 i$, and $1.7+0 i)$ can be easily distinguished. By contrast, the differences between the extinction cross sections of the strongly absorbing aerosol $(m=1.5+0.3 i, 1.6+0.3 i$, and $1.7+0.3 i)$ are much smaller, particularly for $600 \mathrm{~nm}$ diameter particles.

\section{Summary and conclusions}

We have constructed a laboratory instrument that accurately measures aerosol optical extinction in the 360-420 nm spectral range. At each aerosol diameter selected by the DMA, we measure aerosol optical extinction and the concentration of particles, which can be used to calculate the aerosol extinction cross section. By combining multiple measurements of aerosol extinction cross section at different diameters, we are able to retrieve a refractive index as a function of wavelength. 


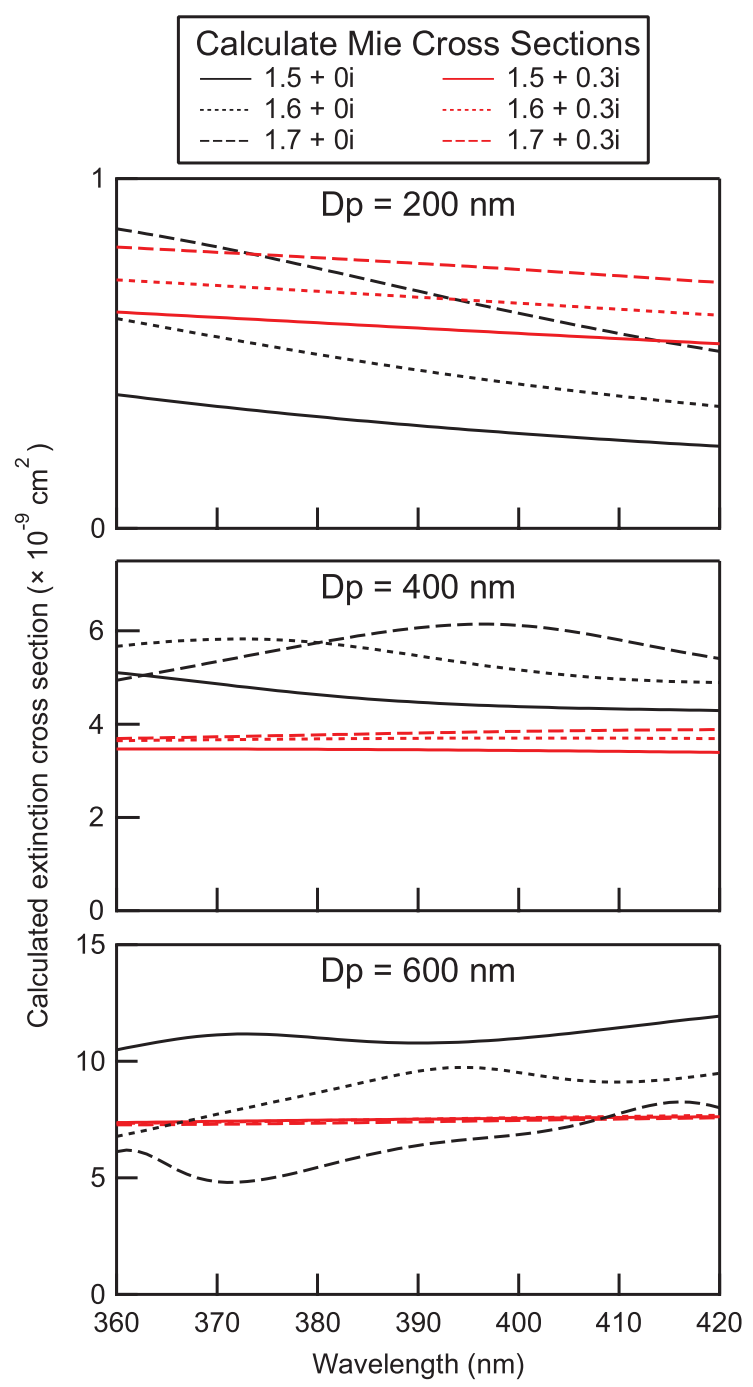

Fig. 11. Theoretical aerosol extinction cross sections for six refractive indices at aerosol diameters of 200, 400, and $600 \mathrm{~nm}$.

We have applied this method to measure aerosol cross sections for different aerosols generated in the laboratory, including PSL, ammonium sulfate, nigrosin, and SRFA aerosol. For each of these compounds, we derive refractive indices that are consistent with results in the literature. Further, these results are the first reported refractive index measurements as a function of wavelength in the ultraviolet and near-visible spectral regions for each of these species. For SRFA we observe a mild spectral dependence in the imaginary part of the refractive index, as has been predicted by bulk solution studies. The refractive index values are directly useful for global radiative models, and this method may be used to measure other unknown aerosol types.

The results presented here suggest three possibilities for a field instrument to measure aerosol optical properties. First, BBCES cavities could be constructed to measure the optical extinction of an ambient aerosol sample as a function of wavelength. This follows the approach of existing CRDS field instruments that operate at a single wavelength and report optical extinction under dry conditions or at a controlled relative humidity (Strawa et al., 2003; Moosmüller et al., 2005; Baynard et al., 2007; Langridge et al., 2011). The strong absorption by gases in the ultraviolet and visible spectral region, particularly by $\mathrm{NO}_{2}$, requires either a correction based on independent measurements of the absorbing species (e.g. Langridge et al., 2011), selective removal of gas-phase absorbers (e.g. using an activated charcoal filter), or fitting the absorptions in the measured spectra. Second, by combining the BBCES cavities with a DMA and $\mathrm{CPC}$ as demonstrated in this work, optical cross sections could be determined for selected aerosol sizes as a function of wavelength. Third, by measuring multiple optical cross sections at different aerosol sizes, the refractive index could be determined as a function of wavelength. Careful consideration of optimum $D_{p}$ setpoints to determine the refractive index, as described in Bluvshtein et al. (2012), would allow an improved time response for this approach. Our current refractive index retrieval assumes that the singly, doubly, and triply charged particles exiting the DMA share the same composition and optical properties, and that they are approximately spherical. In the ambient atmosphere, particles of a single diameter may have different compositions, composition may vary strongly with particle diameter, particles may not be internally-well mixed, and particles may not be spherical. These challenges could be minimized by selecting particles of a single size and density (Beranek et al., 2012). Further, bulk aerosol composition as a function of size and single-particle composition could be quantified with laser mass spectrometry instruments (Pratt and Prather, 2012) to evaluate how these affect the refractive index retrieval.

Each of the three experimental approaches described above provides wavelength-resolved measurements of aerosol optical properties, and could potentially be combined with additional measurements of aerosol composition, aging, hygroscopicity, and other properties to more fully describe aerosol properties and processes in the atmosphere.

Acknowledgements. We thank Andrew Langford for technical discussions. We thank Justin Langridge for his help in developing the BBCES aerosol method. We thank Nicholas Wagner and John Trytko for data acquisition software. RAW, CAB, and SSB acknowledge financial support from the NOAA Atmospheric Chemistry and Climate Program. JMF and YR acknowledge financial support by German-Israeli Science Foundation (GIF, Grant \#1136-26.8/2011) and by FP7-ENV-2010-265148-PEGASOS. YR acknowledges support by the Helen and Martin Kimmel Award for Innovative Investigation. JMF is supported by a research grant from the Jinich Postdoctoral Fellowship.

Edited by: P. Herckes 


\section{References}

Abo Riziq, A., Erlick, C., Dinar, E., and Rudich, Y.: Optical properties of absorbing and non-absorbing aerosols retrieved by cavity ring down (CRD) spectroscopy, Atmos. Chem. Phys., 7, 15231536, doi:10.5194/acp-7-1523-2007, 2007.

Abo Riziq, A., Trainic, M., Erlick, C., Segre, E., and Rudich, Y.: Extinction efficiencies of coated absorbing aerosols measured by cavity ring down aerosol spectrometry, Atmos. Chem. Phys., 8, 1823-1833, doi:10.5194/acp-8-1823-2008, 2008.

Adler, G., Erlick, C., Rudich, Y., and Abo Riziq, A.: The effect of intrinsic organic carbon on the optical properties of diesel soot, P. Natl. Acad. Sci. USA, 107, 6699-6704, 2010.

Andreae, M. O. and Gelencsér, A.: Black carbon or brown carbon? The nature of light-absorbing carbonaceous aerosols, Atmos. Chem. Phys., 6, 3131-3148, doi:10.5194/acp-6-3131-2006, 2006.

Arnott, W. P., Moosmüller, H., Rogers, C. F., Jin, T. F., and Bruch, R.: Photoacoustic spectrometer for measuring light absorption by aerosol: instrument description, Atmos. Environ., 33, 28452852, 1999.

Axson, J. L., Washenfelder, R. A., Kahan, T. F., Young, C. J., Vaida, V., and Brown, S. S.: Absolute ozone absorption cross section in the Huggins Chappuis minimum (350-470 nm) at 296 K, Atmos. Chem. Phys., 11, 11581-11590, doi:10.5194/acp11-11581-2011, 2011.

Ball, S. M., Langridge, J. M., and Jones, R. L.: Broadband cavity enhanced absorption spectroscopy using light emitting diodes, Chem. Phys. Lett., 398, 68-74, 2004.

Bateman, J. B., Weneck, E. J., and Eshler, D. C.: Determination of particle size and concentration from spectrophotometric transmission, J. Coll. Sci., 14, 308-329, 1959.

Baynard, T., Lovejoy, E. R., Pettersson, A., Brown, S. S., Lack, D., Osthoff, H., Massoli, P., Ciciora, S., Dube, W. P., and Ravishankara, A. R.: Design and application of a pulsed cavity ringdown aerosol extinction spectrometer for field measurements, Aerosol Sci. Tech., 41, 447-462, 2007.

Beranek, J., Imre, D., and Zelenyuk, A.: Real-time shape-based particle separation and detailed in situ particle shape characterization, Anal. Chem., 84, 1459-1465, 2012.

Bluvshtein, N., Flores, J. M., Riziq, A. A., and Rudich, Y.: An approach for faster retrieval of aerosols' complex refractive index using cavity ring-down spectroscopy, Aerosol Sci. Tech., 46, 1140-1150, 2012.

Bodhaine, B. A., Wood, N. B., Dutton, E. G., and Slusser, J. R.: On Rayleigh optical depth calculations, J. Atmos. Ocean. Tech., 16, 1854-1861, 1999.

Bohren, C. F. and Huffman, D. R.: Absorption and scattering of light by small particles, Wiley-Interscience, New York, 1983.

Bond, T. C.: Spectral dependence of visible light absorption by carbonaceous particles emitted from coal combustion, Geophys. Res. Lett., 28, 4075-4078, 2001.

Bond, T. C. and Bergstrom, R. W.: Light absorption by carbonaceous particles: An investigative review, Aerosol Sci. Tech., 40, 27-67, 2006.

Bond, T. C., Anderson, T. L., and Campbell, D.: Calibration and intercomparison of filter-based measurements of visible light absorption by aerosols, Aerosol Sci. Tech., 30, 582-600, 1999.

Cappa, C. D., Che, D. L., Kessler, S. H., Kroll, J. H., and Wilson, K. R.: Variations in organic aerosol optical and hygroscopic proper- ties upon heterogeneous OH oxidation, J. Geophys. Res.-Atmos., 116, D15204, doi:15210.11029/12011JD015918, 2011.

Chartier, R. T. and Greenslade, M. E.: Initial investigation of the wavelength dependence of optical properties measured with a new multi-pass Aerosol Extinction Differential Optical Absorption Spectrometer (AE-DOAS), Atmos. Meas. Tech., 5, 709-721, doi:710.5194/amt-5195-5709-2012, 2012.

Chung, C. E., Ramanathan, V., and Decremer, D.: Observationally constrained estimates of carbonaceous aerosol radiative forcing, P. Natl. Acad. Sci. USA, 109, 11624-11629, 2012.

Dinar, E., Riziq, A. A., Spindler, C., Erlick, C., Kiss, G., and Rudich, Y.: The complex refractive index of atmospheric and model humic-like substances (HULIS) retrieved by a cavity ring down aerosol spectrometer (CRD-AS), Faraday Discuss., 137, 279-295, 2008.

Fiedler, S. E., Hese, A., and Ruth, A. A.: Incoherent broad-band cavity-enhanced absorption spectroscopy, Chem. Phys. Lett., 371, 284-294, 2003.

Fierz-Schmidhauser, R., Zieger, P., Wehrle, G., Jefferson, A., Ogren, J. A., Baltensperger, U., and Weingartner, E.: Measurement of relative humidity dependent light scattering of aerosols, Atmos. Meas. Tech., 3, 39-50, doi:10.5194/amt-3-392010, 2010.

Flores, J. M., Trainic, M., Borrmann, S., and Rudich, Y.: Effective broadband refractive index retrieval by a white light optical particle counter, Phys. Chem. Chem. Phys., 11, 7943-7950, 2009.

Flores, M. J., Bar-Or, R. Z., Bluvshtein, N., Abo-Riziq, A., Kostinski, A., Borrmann, S., Koren, I., Koren, I., and Rudich, Y.: Absorbing aerosols at high relative humidity: linking hygroscopic growth to optical properties, Atmos. Chem. Phys., 12, 55115521, doi:10.5194/acp-12-5511-2012, 2012.

French, R. H., Winey, K. I., Yang, M. K., and Qiu, W. M.: Optical properties and van der Waals-London dispersion interactions of polystyrene determined by vacuum ultraviolet spectroscopy and spectroscopic ellipsometry, Aust. J. Chem., 60, 251-263, 2007.

Fuchs, H., Dube, W. P., Lerner, B. M., Wagner, N. L., Williams, E. J., and Brown, S. S.: A sensitive and versatile detector for atmospheric $\mathrm{NO}_{2}$ and $\mathrm{NO}_{\mathrm{x}}$ based on blue diode laser cavity ring-down spectroscopy, Environ. Sci. Technol., 43, 7831-7836, 2009.

Garvey, D. M. and Pinnick, R. G.: Response characteristics of the particle measuring systems active scattering aerosol spectrometer probe (ASASP-X), Aerosol Sci. Tech., 2, 477-488, 1983.

Gherman, T., Venables, D. S., Vaughan, S., Orphal, J., and Ruth, A. A.: Incoherent broadband cavity-enhanced absorption spectroscopy in the near-ultraviolet: Application to $\mathrm{HONO}$ and $\mathrm{NO}_{2}$, Environ. Sci. Tech., 42, 890-895, 2008.

Hecobian, A., Zhang, X., Zheng, M., Frank, N., Edgerton, E. S., and Weber, R. J.: Water-Soluble Organic Aerosol material and the light-absorption characteristics of aqueous extracts measured over the Southeastern United States, Atmos. Chem. Phys., 10, 5965-5977, doi:10.5194/acp-10-5965-2010, 2010.

Heintzenberg, J. and Charlson, R. J.: Design and applications of the integrating nephelometer: A review, J. Atmos. Ocean. Tech., 13, 987-1000, 1996.

IPCC: Climate Change 2007: The Physical Science BasisContribution of Working Group I to the Fourth Assessment Report of the Intergovernmental Panel on Climate Change, edited by: Solomon, S., Qin, D., Manning, M., Chen, Z., Marquis, M., Averyt, K. B., Tignor, M., and Miller, H. L., 289-348, Cambridge 
Univ. Press, New York, 2007.

Kebabian, P. L., Robinson, W. A., and Freedman, A.: Optical extinction monitor using cw cavity enhanced detection, Rev. Sci. Instrum., 78, 063102, doi:10.1063/1.2744223, 2007.

Knutson, E. O. and Whitby, K. T.: Aerosol classification by electric mobility: Apparatus, theory, and applications, J. Aerosol Sci., 6, 443-451, 1975.

Lack, D. A., Lovejoy, E. R., Baynard, T., Pettersson, A., and Ravishankara, A.R.: Aerosol absorption measurement using photoacoustic spectroscopy: Sensitivity, calibration, and uncertainty developments, Aerosol Sci. Tech., 40, 697-708, 2006.

Lack, D. A., Cappa, C. D., Langridge, J., Richardson, M., Law, D., McLaughlin, R., and Murphy, D. M.: Aircraft instrument for comprehensive characterisation of aerosol optical properties, part 2: Black and brown carbon absorption and absorption enhancement measured with photo acoustic spectroscopy, Aerosol Sci. Tech., 45, 555-568, 2012.

Lang-Yona, M., Rudich, Y., Segre, E., Dinar, E., and Abo-Riziq, A.: Complex refractive indices of aerosols retrieved by continuous wave-Cavity Ring Down Aerosol Spectrometer, Anal. Chem., 81, 1762-1769, 2009.

Langford, A. O., Schofield, R., Daniel, J. S., Portmann, R. W., Melamed, M. L., Miller, H. L., Dutton, E. G., and Solomon, S.: On the variability of the Ring effect in the near ultraviolet: understanding the role of aerosols and multiple scattering, Atmos. Chem. Phys., 7, 575-586, doi:10.5194/acp-7-575-2007, 2007.

Langridge, J., Richardson, M., Lack, D. A., Law, D., and Murphy, D. M.: Aircraft instrument for comprehensive characterisation of aerosol optical properties, part I: Wavelength dependent optical extinction and its relative humidity dependence measured using cavity ringdown spectroscopy, Aerosol Sci. Tech., 45, 13051318, 2011.

Liu, B. Y. H. and Lee, K. W.: An aerosol generator of high stability, Am. Ind. Hyg. Assoc. J., 36, 861-865, 1975.

Ma, X. Y., Lu, J. Q., Brock, R. S., Jacobs, K. M., Yang, P., and Hu, X. H.: Determination of complex refractive index of polystyrene microspheres from 370 to 1610 nm, Phys. Med. Biol., 48, 41654172, 2003.

Markowski, G. R.: Improving Twomey algorithm for inversion of aerosol measurement data, Aerosol Sci. Tech., 7, 127-141, 1987.

Massoli, P., Kebabian, P. L., Onasch, T., Hills, F. B., and Freedman, A.: Aerosol light extinction measurements by cavity attenuated phase shift (CAPS) spectroscopy: Laboratory validation and field deployment of a compact aerosol particle extinction monitor, Aerosol Sci. Tech., 44, 428-435, 2010

Mathseon, L. A. and Saunderson, J. L.: Optical and electrical properties of polystyrene in Styrene, Its Polymers, Copolymers and Derivatives, 517-573, edited by: Boundy, R. H. and Boyer, R. F., Reinhold Publishing Corp., New York, 1952.

McComiskey, A., Schwartz, S. E., Schmid, B., Guan, H., Lewis, E. R., Ricchiazzi, P., and Ogren, J. A.: Direct aerosol forcing: Calculation from observables and sensitivities to inputs, J. Geophys. Res., 113, D09202, doi:09210.01029/02007JD009170, 2008.

Miles, R. E. H., Rudic, S., Orr-Ewing, A. J., and Reid, J. P.: Influence of uncertainties in the diameter and refractive index of calibration polystyrene beads on the retrieval of aerosol optical properties using Cavity Ring Down Spectroscopy, J. Phys. Chem. A, 114, 7077-7084, 2010.
Moosmüller, H., Varma, R., and Arnott, W. P.: Cavity ring-down and cavity-enhanced detection techniques for the measurement of aerosol extinction, Aerosol Sci. Tech., 39, 30-39, 2005.

Moosmüller, H., Chakrabarty, R. K., Ehlers, K. M., and Arnott, W. P.: Absorption Ångström coefficient, brown carbon, and aerosols: basic concepts, bulk matter, and spherical particles, Atmos. Chem. Phys., 11, 1217-1225, doi:10.5194/acp-11-12172011, 2011.

Nakayama, T., Matsumi, Y., Sato, K., Imamura, T., Yamazaki, A., and Uchiyama, A.: Laboratory studies on optical properties of secondary organic aerosols generated during the photooxidation of toluene and the ozonolysis of alpha-pinene, J. Geophys. Res., 115, D24204, doi:24210.21029/22010JD014387, 2010.

Nikolov, I. D. and Ivanov, C. D.: Optical plastic refractive measurements in the visible and the near-infrared regions, Appl. Optics, 39, 2067-2070, 2000.

Nilsson, B.: Meteorological Influence on aerosol extinction in the 0.2-40 um wavelength range, Appl. Optics, 18, 3457-3473, 1979.

Pettersson, A., Lovejoy, E. R., Brock, C. A., Brown, S. S., and Ravishankara, A. R.: Measurement of aerosol optical extinction at $532 \mathrm{~nm}$ with pulsed cavity ring down spectroscopy, J. Aerosol Sci., 35, 995-1011, 2004.

Platt, U., Meinen, J., Pöhler, D., and Leisner, T.: Broadband Cavity Enhanced Differential Optical Absorption Spectroscopy (CEDOAS) - applicability and corrections, Atmos. Meas. Tech., 2, 713-723, doi:10.5194/amt-2-713-2009, 2009.

Pratt, K. A. and Prather, K. A.: Mass spectrometry of atmospheric aerosols - Recent developments and applications. Part II: On-line mass spectrometry techniques, Mass. Spectrom. Rev., 31, 17-48, 2012.

Rizzo, L. V., Correia, A. L., Artaxo, P., Procópio, A. S., and Andreae, M. O.: Spectral dependence of aerosol light absorption over the Amazon Basin, Atmos. Chem. Phys., 11, 8899-8912, doi:10.5194/acp-11-8899-2011, 2011.

Shardanand, S. and Rao, A. D. P.: Absolute Rayleigh scattering cross sections of gases and freons of stratospheric interest in the visible and ultraviolet regions, NASA Technical Note, 1977.

Smart, C. and Willis, E.: Determination of refractive indices of polystyrene latices by light scattering, J. Colloid Interf. Sci., 25, 577-583, 1967.

Spindler, C., Riziq, A. A., and Rudich, Y.: Retrieval of aerosol complex refractive index by combining cavity ring down aerosol spectrometer measurements with full size distribution information, Aerosol Sci. Tech., 41, 1011-1017, 2007.

Strawa, A. W., Castaneda, R., Owano, T., Baer, D. S., and Paldus, B. A.: The measurement of aerosol optical properties using continuous wave cavity ring-down techniques, J. Atmos. Ocean. Tech., 20, 454-465, 2003.

Sultanova, N. G., Nikolov, I. D., and Ivanov, C. D.: Measuring the refractometric characteristics of optical plastics, Opt. Quant. Electron., 35, 21-34, 2003.

Sun, H. L., Biedermann, L., and Bond, T. C.: Color of brown carbon: A model for ultraviolet and visible light absorption by organic carbon aerosol, Geophys. Res. Lett., 34, L17813, doi:10.1029/2007GL029797, 2007a.

Sun, H. L., Biedermann, L., and Bond, T. C.: Color of brown carbon: A model for ultraviolet and visible light absorption by organic carbon aerosol, Geophys. Res. Lett., 34, L17813, 
doi:10.1029/2007GL029797, 2007b.

Thalman, R. and Volkamer, R.: Inherent calibration of a blue LED-CE-DOAS instrument to measure iodine oxide, glyoxal, methyl glyoxal, nitrogen dioxide, water vapour and aerosol extinction in open cavity mode, Atmos. Meas. Tech., 3, 1797-1814, doi:10.5194/amt-3-1797-2010, 2010.

Toon, O. B., Pollack, J. B., and Khare, B. N.: The optical constants of several atmospheric aerosol species - Ammonium sulfate, aluminum oxide, and sodium chloride, J. Geophys. Res.-Ocean. Atmos., 81, 5733-5748, 1976.

Trainic, M., Abo Riziq, A., Lavi, A., Flores, J. M., and Rudich, Y.: The optical, physical and chemical properties of the products of glyoxal uptake on ammonium sulfate seed aerosols, Atmos. Chem. Phys., 11, 9697-9707, doi:10.5194/acp-11-96972011, 2011.

Twomey, S.: Comparison of constrained linear inversion and an iterative nonlinear algorithm applied to indirect estimation of particle-size distributions, J. Comput. Phys., 18, 188-200, 1975.

Varma, R. M., Venables, D. S., Ruth, A. A., Heitman, U., Schlosser, E., and Dixneuf, S.: Long optical cavities for open-path monitoring of atmospheric trace gases and aerosol extinction, Appl. Optics, 48, 159-171, 2009.

Vaughan, S., Gherman, T., Ruth, A. A., and Orphal, J.: Incoherent broad-band cavity-enhanced absorption spectroscopy of the marine boundary layer species $\mathrm{I}_{2}, \mathrm{IO}$ and OIO, Phys. Chem. Chem. Phys., 10, 4471-4477, 2008.

Venables, D. S., Gherman, T., Orphal, J., Wenger, J. C., and Ruth, A. A.: High sensitivity in situ monitoring of $\mathrm{NO}_{3}$ in an atmospheric simulation chamber using incoherent broadband cavity-enhanced absorption spectroscopy, Environ. Sci. Technol., 40, 6758-6763, 2006. von der Weiden, S.-L., Drewnick, F., and Borrmann, S.: Particle Loss Calculator - a new software tool for the assessment of the performance of aerosol inlet systems, Atmos. Meas. Tech., 2, 479-494, doi:10.5194/amt-2-479-2009, 2009.

Wang, S. C. and Flagan, R. C.: Scanning Electrical Mobility Spectrometer, Aerosol Sci. Tech., 13, 230-240, 1990.

Washenfelder, R. A., Langford, A. O., Fuchs, H., and Brown, S. S.: Measurement of glyoxal using an incoherent broadband cavity enhanced absorption spectrometer, Atmos. Chem. Phys., 8, 7779-7793, doi:10.5194/acp-8-7779-2008, 2008.

Weingartner, E., Saathoff, H., Schnaiter, M., Streit, N., Bitnar, B., and Baltensperger, U.: Absorption of light by soot particles: determination of the absorption coefficient by means of aethalometers, J. Aerosol Sci., 34, 1445-1463, 2003.

Wiedensohler, A.: An approximation of the bipolar charge distribution for particles in the sub-micron size range, J. Aerosol Sci., 19, 387-389, 1988.

Zhang, X. L., Lin, Y. H., Surratt, J. D., Zotter, P., Prevot, A. S. H., and Weber, R. J.: Light-absorbing soluble organic aerosol in Los Angeles and Atlanta: A contrast in secondary organic aerosol, Geophys. Res. Lett., 38, L21810, doi:10.1029/2011GL049385, 2011. 